\title{
Brayton Power Conversion System
}

\section{Final}

Final Scientific Report to be submitted to OSTI

July 15, 2011

DOE Contract \# DE-FC36-08G018029/A000

Brayton Energy, LLC Hampton, NH 03842 


\title{
Final Scientific Report to be submitted to OSTI
}

\author{
Project Title: $\quad$ Brayton Solar Power Conversion System \\ Covering Period: $\quad$ (March 1, 2008 to March 31, 2011) \\ Date of Report: (July 15, 2011) \\ Recipient: Brayton Energy, LLC \\ Award Number: $\quad$ DE-FC36-08GO18029/A000
}

Working Partners: ORNL

Cost-Sharing Partners: Southwest Solar Technologies

Contacts:

Jim Kesseli

Phone: 6036010450 x202

Fax: 603-967-4027

Email: Kesseli@Braytonenergy.com

DOE Project Team:

\author{
DOE Contracting Officer \\ DOE Field Project Officer \\ Senior Project Engineer
}

Eric Vollnogle

603-601-0450 x205

603-967-4027

Eric@Braytonenergy.com

\section{Project Objective:}

The objective of the project is to demonstrate the viability and economics of a new dishBrayton concentrating solar thermal power conversion system which incorporates energy storage and optional fuel-co firing. The project will focus on designing and testing the power conversion system.

\section{Background:}

Brayton Energy completed Phase 1 of this program in March 2009, delivering an extensive design report. Phase 2, completed in July 2012, concentrated on fabrication and test of the major subassemblies, including the solar receiver, and turbo-alternator. In parallel a fully-functional parabolic dish concentrator has been built and tested, entirely supported by private funds from Southwest Solar Technologies. The program was originally supported by Arizona Public Service, the California Energy Commission, Southern California Gas Co/SEMPRA, and Brayton's internal R\&D. APS and Southern California Gas/SEMPRA continue their involvement in the program as strategic partners. 


\section{Table of Contents}

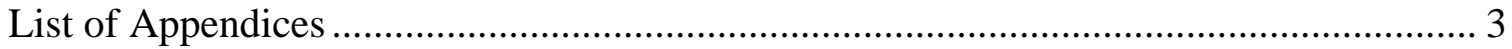

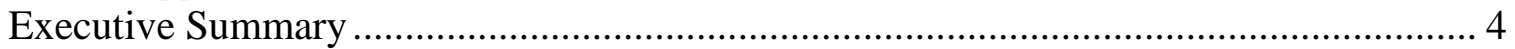

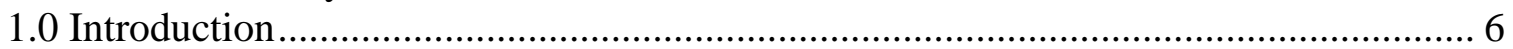

2.0 Statement of Project Objectives and Results ..............................6

3.0 Conclusions and Recommendations 29

\section{List of Appendices}

A - SolarCAT and Dish-Brayton schematics and assumptions

B - Preliminary Mechanical Design of the Turbo-Alternator, performed in Phase 1

$\mathrm{C}$ - Preliminary Solar Receiver Design, prepared in Phase 1 


\section{Executive Summary}

This report contains the results of work performed in on Phase 1 and Phase 2 related to the Brayton Solar Power Conversion System project. The SolarCAT (Solar Compressed Air Turbine) is dish-engine module with compressed air energy storage. It generates 200-kWe peak power, employing a 320 sq. meter dish. Designed for multi-MW arrays, the power plant provides utility load-profile shaping as well as efficient solar power conversion. At the discretion of the utility operator, the gas turbine also operates on a wide range of fuels (bio and fossil) to supplement solar power or provide non-solar operation. A brief description of the principal subassemblies follows:

- The "engine" is a compact turbo-alternator operating with only air serving as the working fluid, the lubricant, and the coolant. The turbo-alternator has been designed to be maintenance-free for the 20-year (60,000 hour) life.

- The solar receiver is a tubular design incorporating mature heat exchanger design practices. ORNL has been instrumental in evaluating materials for this application.

- The tracking solar concentrator (Dish) was developed and installed at Southwest Solar Technologies ${ }^{1}$, by private funding. The unit constructed for Phase 2 has a collection area of approximately 320 sq meters.

The critical subassemblies of the system have been fabricated and tested in Phase 2 of this program. Each subsystem was purpose-built for this new power generation system. This included a special turbo-alternator system built with air bearings, a very compact recuperator, a hybrid combustor, and a solar receiver fully integrated for installation on the SST dish. The receiver was tested alone on the dish. The extensive testing of the turbomachinery, dish and receiver conducted on this program has overcome common development issues. Furthermore, the team has worked exceptionally hard to prove the performance and cost basis of the system. Reliable subsystems have been checked-out and are ready to be move into the complete engine-dish module in Phase 3. In parallel, several economically-driven component upgrades have been identified which improve efficiency and lower cost. The project was terminated prior at the end of Phase 2, to installing the special purpose recuperated turbo-alternator on the dish.

\section{Summary of Accomplishments}

The SolarCAT system was designed and portions of the system were tested, including the purpose-built turbo-alternator and the solar receiver.

Extensive testing of the turbo-alternator was performed in Brayton's lab, demonstrating over 100 hours of reliability, and characterizing the turbomachinery, air bearings, and shaft speed alternator.

- Turbine efficiencies met SOPO efficiency targets (80\%).

- Alternator efficiency met SOPO targets (96\%)

\footnotetext{
${ }^{1}$ Formally SolarCAT Incorporate, name changed in Jan 2011
} 
- Endurance testing roughly doubled the SOPO target of 50 hours

- Manufacturing studies confirmed the product cost targets will be met

The solar receiver is designed to operate with a new class of high-temperature economical metallic alloys and a novel low-cost quartz window.

- Brayton focused on the performance characterization of the so-called Alpha design, using readily available stainless steel. A heat loss test rig and on-sun testing indicate that the receiver efficiency target (SOPO) of $86 \%$ was met at the normal rating conditions of $850 \mathrm{~W} / \mathrm{m} 2$.

- An in-depth pricing model for the receiver as fabricated, identified design improvements, and the supporting capital equipment needs has confirmed that cost target can be met.

The parabolic dish concentrator built and tested for this program (but not on the program) is among the largest ever constructed. It serves as test-bed for on-going receiver and PCU testing. The experience gained in this non-federally funded element of the program serves as a basis for a future advanced dish development program at Southwest Solar Technologies.

The levelized cost of energy (LCOE) for the SolarCAT system has been evaluated for a specific site in Glendale AZ on land purchased by SST. The team has developed a detailed database for the product, installation, and site preparation. The methodology and financial assumptions strictly follow that established in the System Advisory Model (SAM). The results of the analysis indicate several scenarios wherein the LCOE is at or below $\$ 0.10 / \mathrm{kWH}$ for our first $100 \mathrm{MW}$ plant in Glendale AZ. 


\subsection{Introduction}

This report is intended document the work performed in Budget Periods 1 and 2, starting in January 2008 through March 2011. Phase 1 focused on the design of the turboalternator and the solar receiver. Phase 2 focused on the fabrication of the turboalternator and solar receiver and the execution of detailed sub-system test plans. In parallel, without federal funding, Southwest Solar Technology (SST) designed, deployed and tested a suitable dish to enable receiver testing.

The schematic for the Brayton Solar Power Conversion System is shown in Figure 1. The system employs a large industrial central compression station, operating at off-peak hours, to compressor air into a vessel or geological formation. Compressed air energy storage (CAES) is a well-known energy storage technique which provides utility-scale load leveling. This project focused on the development of the hybrid solar-activated CAES system. Appendix A provides some background on CAES system, along with tabulated rating conditions for each state-point.

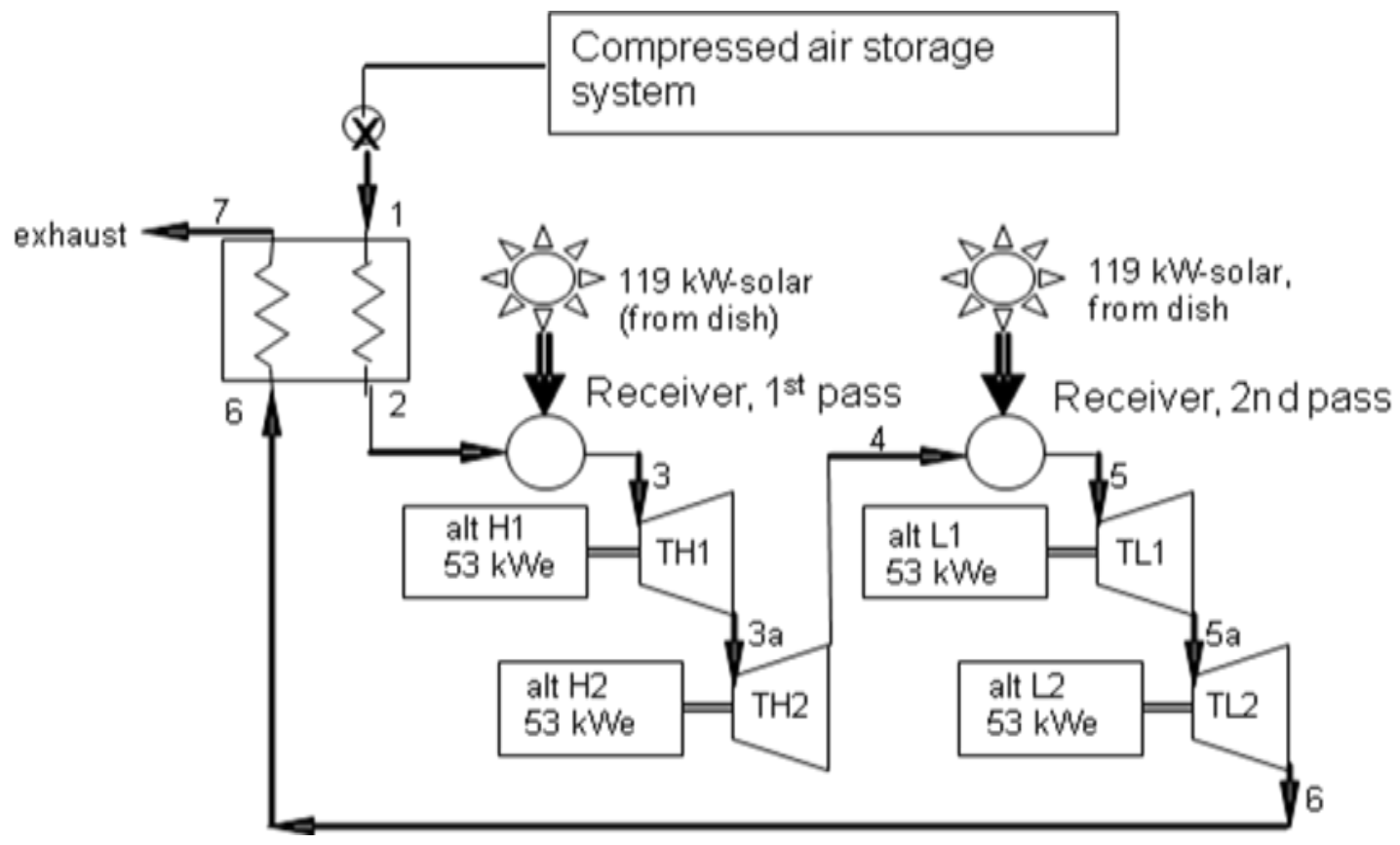

Figure 1 - Schematic of the Brayton Solar Power Conversion System; a hybrid solar compressed air energy storage power plant. The power conversion system employs four nearly identical $53 \mathrm{kWe}$ turbo-alternator modules, with each stage fitted with a custom turbine housing and turbine blade design. 


\subsection{Statement of Project Objectives and Results}

Phase 1 focused on the preliminary design of the SolarCAT system. The Phase 1 SOPO called for the completion of the Preliminary Design of the turbo-alternator and solar receiver. This preliminary design is presented in Appendix B, for the turbo-alternator and Appendix $\mathrm{C}$ for the solar receiver. In Phase 2, the SOPO emphasized testing and more detailed analysis of the system performance. After fully analyzing the system and its components, fabricating every element of the final system, and performing validation testing on each subassembly, the team was well-positioned to forecast the system performance and cost. The final LCOE is presented for a scenario in Glendale Arizona; a location that had been selected for a pilot plant. Each task summary below starts with the recitation of the Statement of Project Objective (SOPO) in italics.

\subsection{Demonstrate turbine efficiencies in multistage turbo- expander}

SOPO: The turbine and hot section will be fabricated and tested on the turbo-alternator test rig. The goal of the product is to achieve an adiabatic turbine efficiency $>84 \%$. The lab test rig at Brayton will be fired by custom-designed SolarCAT hybrid burners. For the Budget Period 2 Go/No-Go decision, the early turbine efficiency targets for the initial test trials in this phase have been set at $>80 \%$.

\section{Technical Discussion}

As built, SolarCAT turbo-alternator is composed of four turbines arranged in series. Each turbine is integrated with a similar alternator and mechanical system. This approach was selected to lower the nonrecurring development cost by standardizing on a single alternator and air bearing mechanical system. Nevertheless, this design choice results in a significant aerodynamic compromise for the turbines.

The early decision was made to divide the nominal $200 \mathrm{kWe}$ of electrical power potential into four equal stages. This was a very conservative choice based on the availability 50 $\mathrm{kWe}$ alternators from two suppliers. Subsequent design work has been performed on a two-stage version of the product, composed of two $100 \mathrm{kWe}$ turbo-alternators. The two stage product significantly relieves some of the aerodynamic compromises in the turbines. In addition to efficiency advantages, a next generation 2-stage system would also be less expensive. .

The tests were performed on a combustion-fired recuperated laboratory test rig, illustrated schematically in Figure 2.1. The testing followed industry standards for turbine testing. The complete test plan, was delivered to the DOE/NREL/SNLA project monitors in advance of the testing. 


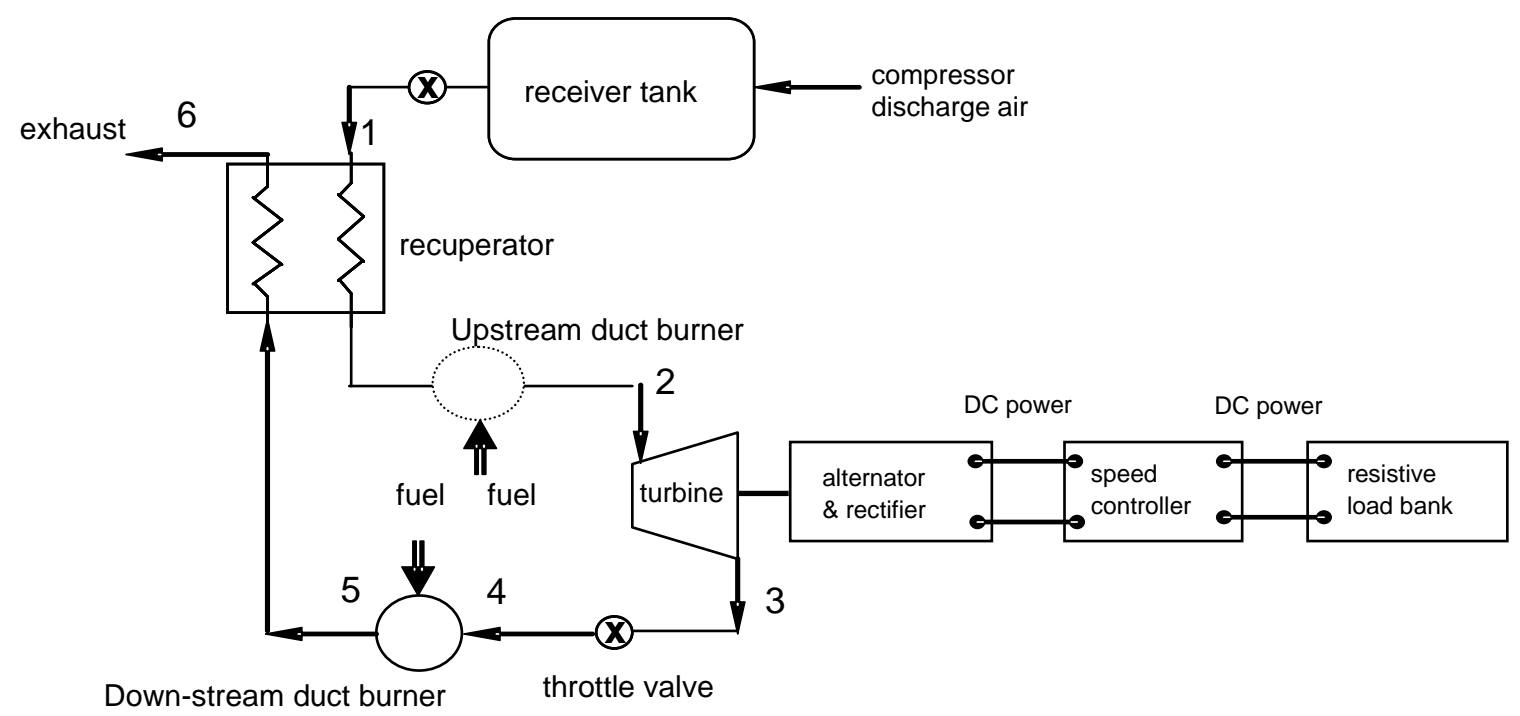

\begin{tabular}{|c|c|c|}
\hline station & Imeasured quantity & sensor \\
\hline 1 & stage massflow & coriolis meter \\
\hline 2 & stage-inlet total pressure & 2 kiel probes \\
\hline 2 & stage-inlet total temperature & 3 thermocouples \\
\hline 3 & stage-exit total pressure & 3 kiel probes \\
\hline \multirow[t]{5}{*}{3} & stage-exit total temperature & 6 thermocouples \\
\hline & rotational speed & controller digital signal \\
\hline & \begin{tabular}{|c|} 
alternator DC power \\
- output current \\
- output voltage \\
\end{tabular} & $\begin{array}{l}\text { controller digital signal } \\
\text { controller digital signal }\end{array}$ \\
\hline & nozzle-vane position & actuator digital signal \\
\hline & barometric pressure & precision pressure gauge \\
\hline
\end{tabular}

Figure 2.1 - Schematic of turbine test rig, indicating the principal measurements. This test facility was also used to gather bearing loss data and alternator performance measurements.

The testing was performed to acquire the most accurate measurement of the adiabatic turbine efficiency. The adiabatic efficiency is the metric that compares the actual work extraction form the flow against the theoretical work obtainable under isentropic conditions.

$$
\eta_{t}=\frac{T_{02}-T_{03}}{T_{02}\left[1-\left(P_{02} / P_{03}\right)^{\left(v_{-1}\right) / v}\right]}
$$

Equation 1

Where the temperatures and pressure state-point are defined on Figure 2.1, and $\eta_{\mathrm{t}}=$ turbine total-total isentropic efficiency 
$\gamma=\mathrm{cp} / \mathrm{cv}$, the gas constant

The greatest challenge in testing small turbomachinery is the inherently non-adiabatic conditions associated with rotor flow path. Furthermore, in a radial turbine, the work extraction is a function of the radius, creating a radial temperature gradient at the exit. The five principal sources of error are summarized below:

1. Non-adiabaticity: The high surface area to volume ratio of the small flow path coupled with the steep temperature gradient in the metal housing and rotor deviates from the adiabatic assumption. The error associated with this effect is inversely proportional to the diameter of the turbine rotor. The turbines tested are very small by industry standards.

2. To obtain T2 in Equation-1, the exit temperature and mass profile of the radial turbine should be measured to establish a mass-averaged temperature. This requires multiple thermocouples. However in a very small turbine, (the passage height in Stage-1 is only $12 \mathrm{~mm}$ ), it is not possible to sufficiently populate the exit passage with thermocouple probes, without impeding the gas flow.

3. When firing with a laboratory burner to design conditions $(1200 \mathrm{~K}, 1700 \mathrm{~F})$, the exiting gas is inclined to have some temperature variability.

4. At elevated temperature, the thermocouples are influenced by the temperature and the view-factor to the passage walls. In small, high temperature operation, the gas temperature may not be in equilibrium with the walls.

5. Thermocouple errors, typically bench-marked at $+/-2.2{ }^{\circ} \mathrm{C}$ (or $0.75 \% \mathrm{FS}$ ). With calibration that number was reduced, yet still in our small size of the gas passages, it's difficult to insert more than three thermocouples in the gas stream. By contrast, a typical gas turbine might employ 10 or 20 thermocouples to improve accuracy and resolution.

It should be pointed out that these are not inherent sources of inefficiency; rather they are indications of the exceptional challenges associated with measuring the efficiency for the small SolarCAT turbines. After initial testing where these factors resulted in error bars (uncertainty) of over $10 \%$, refinements were made to address each of these effects. The industry-accepted solution is to perform the turbine testing at depressed inlet temperatures applying aerodynamic dimensional similitude. Lowering the inlet temperature substantially reduces the errors associated with the top four error sources above. Testing in air, the two relevant similitude parameters are Mach and Reynolds Numbers. Additionally, locating the burner down stream of the turbine test, and delivering the heat to the air through a heat exchanger is a means leveling the inlet air temperature. The complexity of implementing this procedure is more practical at lower temperatures. An additional benefit is that the down-stream combustor enables the turbine characterization to be performed with pure air, rather than combustion products. This is more accurate because it avoids correction factors associated with the specific heat ratio of the combustion products; so-called gamma factor, $(\gamma=\mathrm{cp} / \mathrm{cv})$. Table 2.1 shows the ratio of the similitude parameters and prescribed test conditions. 


\begin{tabular}{|r|r|r|r|r|}
\hline & Stage-1 & \multicolumn{1}{l|}{ Stage-2 } & \multicolumn{1}{l|}{ Stage-3 } & Stage-4 \\
\hline Design conditions & & & & \\
\hline Inlet temp, K & 1183.2 & 1007.8 & 1199.8 & 1024.9 \\
\hline Outlet temp, K & 1002 & 868.3 & 1033.2 & 884.3 \\
\hline Outlet pressure, Kpa & 912.8 & 445.3 & 201.2 & 98.1 \\
\hline Inlet pressure, Kpa & 2077.5 & 912.8 & 422.1 & 201.2 \\
\hline Speed, RPM & 116000 & 104700 & 109900 & 100000 \\
\hline mass flow (kg/s) & 0.272 & 0.272 & 0.272 & 0.272 \\
\hline Inlet temp, K & 437.2 & 621.5 & 602.1 & 1030.8 \\
\hline Outlet temp, K & 393 & 531.6 & 513.1 & 875.2 \\
\hline Outlet pressure, Kpa & 479.2 & 279.9 & 280.5 & 107.5 \\
\hline Inlet pressure, Kpa & 872.5 & 583.9 & 139.6 & 244.1 \\
\hline Speed, RPM & 59800 & 79800 & 76900 & 111800 \\
\hline mass flow (kg/s) & 0.24 & 0.249 & 0.254 & 0.351 \\
\hline Mach No._inlet & 1.28 & 1.12 & & 1 \\
\hline Figures are test/design point & & & & 1.07 \\
\hline Expansion Ratio & 0.8 & 1.02 & 0.96 & 1.11 \\
\hline
\end{tabular}

Table 2.1 - Aerodynamic similitude is achieved by matching Mach Number, and using the identical working fluid (air). Reynolds number is sufficiently high in both cases to ignore its impact on boundary layer and related skin friction. The traditional nondimensional parameters of $\mathrm{U} / \mathrm{CO}$ and specific speed are matched for all cases.

Each of the four unique turbine rotors and housings were tested, using an external compressed air source, and firing the rig with a propane combustor to achieve the steadystate operating conditions shown in Table 2.1. All turbines were tested at a range of Mach numbers. Stage-1, the weakest performer was found to have an improved efficiency at a slight increase in Mach number. The test results are summarized in Table 2.2. Further details of the turbine testing are found in the appendices listed at the end of this chapter.

\begin{tabular}{|c|c|c|c|c|}
\hline \multicolumn{5}{|c|}{ Turbine Adiabatic Efficiency, $\boldsymbol{\eta}$} \\
\hline Stage & $\begin{array}{l}\eta \text { Analysis } \\
\text { prediction }\end{array}$ & $\eta$ Test & $\begin{array}{l}\text { Error band } \\
+/-\%\end{array}$ & $\begin{array}{l}\eta \text { SOPO } \\
\text { target }\end{array}$ \\
\hline 1 & $79.0 \%$ & $64.8 \%$ & $6.4 \%$ & $80 \%$ \\
\hline 2 & $83.0 \%$ & $79.1 \%$ & $5.4 \%$ & $80 \%$ \\
\hline 3 & $86.0 \%$ & $84.5 \%$ & $6.1 \%$ & $80 \%$ \\
\hline 4 & $84.0 \%$ & $82.7 \%$ & $5.9 \%$ & $80 \%$ \\
\hline
\end{tabular}

Table 2.2 - Summary of total-total adiabatic turbine efficiency $(\eta)$ measurements, predictions, and the SOPO target. 
To obtain an alternate assessment of the rotor work and hence efficiency, the exit flow angle was measured with a cobra probe. This method which requires an accurate mass flow rate measurement was used to check temperature-based definition efficiency measurements. To obtain a defensible efficiency measurement by this method requires the flow angles to be measured with a traversing probe over the trailing edge of the turbine blade. Again, this is manageable with larger turbomachinery, but impractical with normal probe dimensions in our small passage. The efficiency measured at the RMS radius by this method was a good check and diagnostic tool.

The efficiency measurements are the culmination of over 80 individual tests and 100 test hours. Many of the rotors were tested multiple times; each time making adjustments and recalibrations of the instruments. Two different Stage-3 rotor geometries were tested; one trimmed from a commercial turbocharger rotor and a second custom design as described in the Phase-1 Report. Stages 1 and 3 operated with variable position nozzles, allowing some variation of parameters while under test. Stages 2 and 4 are fixed geometry with nozzle-less volutes; thus providing no variability during test. Due to cost and processing time constraints, any flaws that were discovered during the testing related to the volute or the rotor were uncorrectable. These deficiencies include the common manufacturing defects and design iterations:

- Blade-shroud clearance gap

- Turbine back-face clearance gap

- Turbine back-face scallop depth

- Blade surface finish

- Nozzle-less housing area ratio

Each of these factors contributed to short-fall in efficiency relative to the NASA and TurbAero ${ }^{\mathrm{TM}}$ model predictions. A short discussion of the impacts of these factors follows. It should be emphasized that each of these factors are addressable and subject to improvements in subsequent iterations or by simply advancing to more refined production tooling.

The for the first test articles, it is generally precautionary to allow over-sized rotor clearances to accommodate machining errors and unanticipated warpage at high temperatures. With experience and manufacturing refinements the clearances are generally improved. On the back-face clearance, we admit that we grossly underestimated its impact on the stage efficiency. The clearance ratio (gap / passage width) was clearly increasingly more of a problem for the progressively smaller passage widths of the high-pressure stages; 1 and 2 . Table 2.3 summarizes the measured clearances and their impact on turbine efficiency.

CLEARANCE EFFECTS
\begin{tabular}{|c|r|r|r|r|}
\hline Stage & $\boldsymbol{\Delta} \boldsymbol{\eta}$ radial & $\boldsymbol{\Delta} \boldsymbol{\eta}$ axial & $\boldsymbol{\Delta} \boldsymbol{\eta}$ backface & $\boldsymbol{\eta}$ corrected \\
\hline 1 & $1.4 \%$ & $12.8 \%$ & $5.0 \%$ & $78.9 \%$ \\
\hline 2 & $0.20 \%$ & $1.10 \%$ & $4.50 \%$ & $85.0 \%$ \\
\hline 3 & $0.20 \%$ & $0.70 \%$ & $1.70 \%$ & $87.1 \%$ \\
\hline
\end{tabular}




\begin{tabular}{|l|l|l|l|l|}
4 & $0.50 \%$ & $0.00 \%$ & $2.80 \%$ & $86.2 \%$ \\
\hline
\end{tabular}

Table 2.3 - The study compares the actual tested clearances in the turbine shroud (radial and axial) and the backface to the design targets for normal microturbines operating at this temperature. Adjusting this clearance ratio in the NASA prediction models indicates that the efficiencies of the tested turbines were significantly compromised by excessive clearances. The very large clearance ratios of the Stage- 1 were outside the range of acceptance for the correlation.

The post-test inspection of turbine housings fired to full temperature demonstrated good thermal stability and minimal mechanical distortion. This suggests that tighter clearances could be machined into new housing castings. Some of the efficiency gains shown in Table 2.3 should be achieved.

The most challenging aerodynamic design is Stage-1, which is distinguished by its low specific speed of approximately $0.35^{2}$, and characteristically narrow blade tip. The low specific speed was dictated by the intent to build all four stages on the common $50 \mathrm{~kW}$ mechanical assembly. This forced the Stage-1 rotor to be larger and slower that optimal. Though the NASA RTD ${ }^{3}$ models indicated that the target efficiency of $80 \%$ was achievable, we have reasons to believe that the models are not well-validated at these conditions.
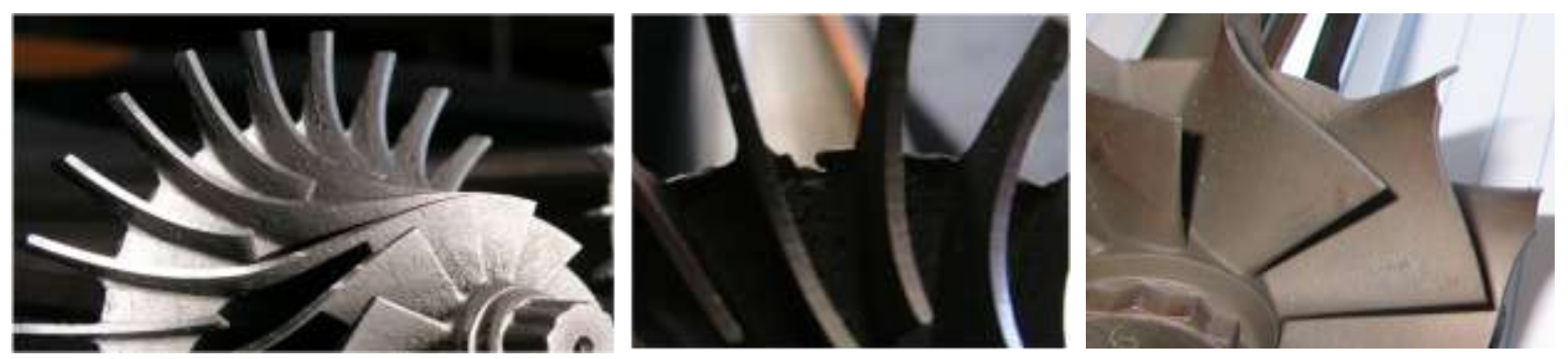

Figure 2.2 - Photos of the Stage 1 (left and center) and Stage 4 (right). Stage 1's narrow blades, poor surface finish, and poor casting quality are evident in the prototypes.

This deficiency in Stage-1 is correctable by either of three strategies.

- The current four-stage turbo-alternator was selected to allow the use of an existing $50 \mathrm{kWe}$ high-speed alternator. This reasoning will be discussed in Section 2.92. The proposed new two-spool turbo-alternator system results in larger rotor dimensions, which will improve the blade clearance ratio.

Combining this change with a slight reduction in stage expansion ratio (enthalpy) will move the specific speed parameter back towards a region of improved efficiency.

- A shrouded turbine rotor is a proven method to mitigate tip clearance losses. This results in elevated rotor stresses. More detailed work would be required to

\footnotetext{
${ }^{2}$ Specific speed is a nondimensional parameter commonly used in turbomachinery design. It is rotational speed $* \sqrt{ }$ volume flow/[isentropic enthalpy $]^{\wedge} 0.75$

${ }^{3}$ NASA's RTD code is a public domain software program used to design and analyze radial inflow turbines.
} 
assess the life of the shrouded rotor. There is also a manufacturing cost increase which steered us away from this solution.

- An alternative or possibly combined strategy for improved efficiency would be to substitute the single Stage-1 radial turbine rotor with a 2-stage axial turbine. The axial turbine is less affected by the low specific speed, and modeling using either the NASA axial turbine code or the TurbAero ${ }^{\mathrm{TM}}$ code show dramatic efficiency improvement over the current radial turbine.

Stage-2 also demonstrated efficiencies slightly below target. The clearances and poor surface finish (like Stage 1) are identified and correctable deficiencies. The principal problem would be mitigated by combining the Stage- 1 and 2 into a single stage as proposed in Section 2.92.

Conclusions: The testing of four turbine rotors was performed with extreme care and attention to details. Still, the cumulative instrument errors and the challenges of testing such small parts led to results with relatively wide error-bars. Turbine efficiencies over the SOPO target $80 \%$ were achieved for two of the four stages. With tighter clearances, Stages 1 and 2 will certainly gain several percentage points. However, new cast and machined turbine parts will be required to correct the clearance short-fall, and for cost reasons, that step has been deferred. A tremendous amount of experience was gained in the execution of this program, providing several defensible paths for achieving the overall turbine efficiency goals.

\subsection{Demonstrate alternator efficiencies}

SOPO: The high speed alternator will be fabricated and tested on the turbo-alternator test rig. The goal of the program is to achieve an efficiency of $>96 \%$. The Lab Test Rig will use a DC load bank, deferring the inverter to Budget Period-3.

\section{$\underline{\text { Technical Discussion }}$}

The alternator used in this project was samarium cobalt permanent magnet type with a high-strength nickel alloy sleeve. The $54 \mathrm{kWe}$ unit was previously designed for another application and adopted to the SolarCAT application. As reported in Phase 1 report, the analysis presented by the supplier, indicated a shaft to DC electric efficiency of $97 \%$ at the rated max power design point. Scaling from this supplied data point, Brayton generated a part-load map for this alternator, to be used in the system analysis, provided in the Phase 1 Report. As is typical, the alternator efficiency declined slightly with input power.

Brayton performed a re-design of the mechanical elements of this alternator to extend its speed range to the target 116,000 RPM. This involved an increase in the sleeve thickness and an increased pre-load on the magnets. The performance models showed no impact on efficiency for either of these changes. 
The testing of the alternator was performed on the turbo-alternator test rig described in the previous section. While most of the turbine efficiency measurements were performed in the mid power range of the alternator, its max (SOPO) efficiency can only be realized at max power. That test rig measured the turbine power from thermodynamic parameters and the electrical power. The alternator losses were deduced by subtraction. Two additional losses were derived to isolate the alternator losses: 1) the rectifier $\left(I^{2} R\right)$ and 2) the bearings.

The net efficiency of the turbo-alternator is the product of the three quantities.

$$
\eta t a=\eta a * \eta t * \eta b * \eta x
$$

Equation 2

where:

Net turbo-alternator efficiency $=\eta$ ta (measured)

Alternator $=\eta$ a (obtained by subtraction)

Turbine adiabatic efficiency $=\eta t$ (measured)

Bearing efficiency $=[(1$-bearing losses $) /$ shaft power $]=\eta b$ (measured)

Rectifier efficiency $=[(1-$ rectifier losses $) /$ shaft power $]=\eta \times$ (measured $)$

The strategy, as indicated above, is to derive the alternator efficiency by measuring the four other quantities. As will be shown, the

The losses in the complete mechanical are attributable to the bearings and windage. The air bearing system was measured by driving the complete mechanical assembly with the turbine. In this case a demagnetized alternator rotor was installed and the turbine served as a dynamometer. Figure 2.3 shows the bearing losses over the operating speed range $(60,000$ RPM to 120,000 RPM). The testing was performed within this range of moderate axial thrust levels. The thrust was adjusted by varying the pressure on the stub end of the alternator. The test methodology allowed a limited control over the thrust, roughly covering the range expected in Stages 3 and 4. After numerous trials, and considering the width of the error bands, it was concluded that the power measured was insensitivity to the axial thrust in the range tested. 


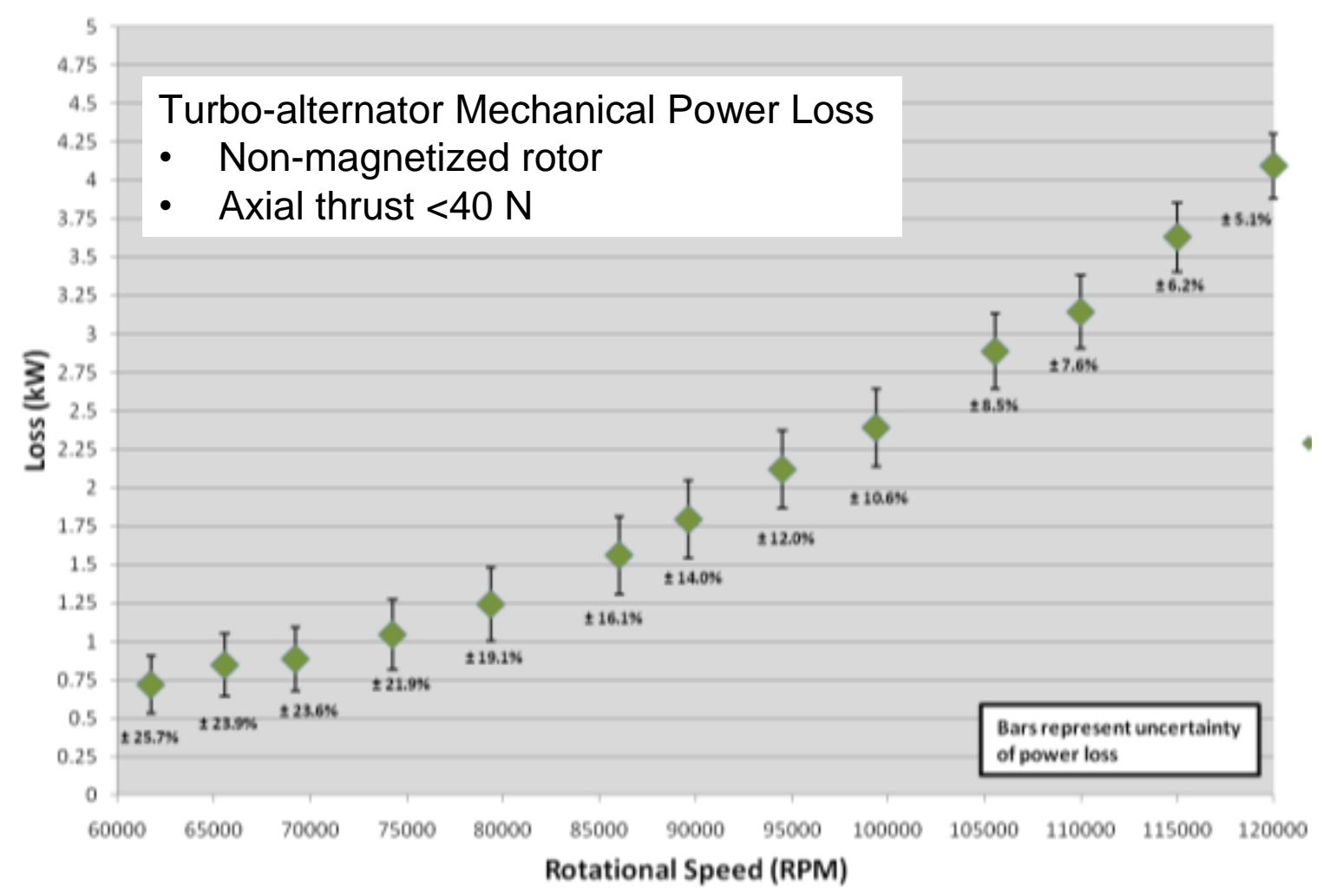

Figure 2.3 - Total windage and bearing losses of the turbo-alternator system, measured over the operating speed range.

The rectifier power losses were derived by measuring the resistance of the rectifier. In all cases the resulting magnitude of the power loss is very low, on the order of 1 to $2 \%$.

The test-bed for the turbo-alternator efficiency measurement was Stage-4, operating at rated temperature, pressure, and flow. This turbine was selected because it operates with very low axial thrust, thus enabling the use of the derived bearing loss correlation. Table 2.4 presents the results of the testing. 


\begin{tabular}{|c|c|c|}
\hline Power, (kW) & Value & Notes \\
\hline DC power (kW) & 38.7 & Measured \\
\hline Rectifier loss (kW) & 0.7 & Electrical resistance I2R \\
\hline PMA AC power (kW) & 39.4 & From subtraction \\
\hline Turbine power $(\mathrm{kW})$ & 42.2 & Measured (m cp DT) \\
\hline Bearing power (kW) & 2.8 & From bearing measurement correlation \\
\hline Alternator loss (kW) & 0.1 & From subtraction \\
\hline Alternator efficiency (without rotor windage) & $99.8 \%$ & From subtraction \\
\hline Alternator efficiency (with rotor windage) & $98.8 \%$ & Based on rough estimate of rotor windage $\sim 1 \mathrm{pct}$ \\
\hline Alternator prediction by vendor & $97.10 \%$ & Presented in Phase 1 report \\
\hline $\begin{array}{l}\text { Phase } 1 \text { alternator prediction used in system } \\
\text { (LCOE) models }\end{array}$ & $93.8 \%$ & \begin{tabular}{|l|} 
The overall cycle performance model uses \\
conservative assumptions and extrapolations
\end{tabular} \\
\hline Uncertainty factors & Error +/- & \\
\hline Power meter & $0.25 \%$ & \\
\hline mass flow meter & $0.21 \%$ & Coriolis \\
\hline Thermocouple error & $8.52 \%$ & Type - K \\
\hline Temp profile error & $5.37 \%$ & from burner and heat loss \\
\hline Rectifier loss uncertainty & $0.17 \%$ & \\
\hline Bearing loss uncertainty & $1.81 \%$ & \\
\hline RMS error & $10.24 \%$ & RMS of above errors \\
\hline
\end{tabular}

Table 2.4 The alternator efficiency, excluding its rotor windage, is derived from subtraction of other mechanical and electrical losses.

It should be noted that the alternator prediction models employed in Phase 1, which predicted an efficiency of $97.1 \%$, included the windage losses of the smooth rotor rotating inside the stator. In the above book-keeping, that loss is included in the bearing loss measurement. Since the bearing losses account for $6.6 \%$, and given the error bars, the residual attributable to the alternator looses is literally in the noise. Bearing loss calculations indicate that the rotor windage should be relatively small as compared to the isolated bearing loss. For rough assessment, it might be 0.5 to 1 percentage point at max speed.

Due to the small measured quantities, relative to the turbine power, the error analysis for the alternator shows fairly wide uncertainty band. Several attempts were made reduce the uncertainty by locating a torque device between the turbine and alternator housings. Care was taken in the fabrication of this test article, however in two attempts the system failed at high speed. The cause was most certainly due to minute misalignment in the stack-up between the turbine and alternator rotors groups. With this experience, a revised design was conceived, but not tested.

Conclusion: Alternator testing was performed with extreme care and attention to details, measuring the very small quantities of power lost in the bearings, rectifier while operating at full power. The alternator efficiency was shown to exceed the SOPO target of $96 \%$ at rated power and speed. The most complete set of data indicates efficiency over $98 \%$. It is important to note that though the error bars are wide, the overall net efficiency of the turbo-alternator is the product of the four efficiency quantities. Therefore if one quantity is under predicted, likely another quantity is over predicted. 
For example, if the alternator efficiency is decremented by a point to line-up with predictive models, the turbine efficiencies would likely be roughly a point higher.

\subsection{Characterize control variables, using variable area turbine nozzle}

SOPO: The objective of this task is to validate turbine efficiency prediction models. The goal is to show that the Brayton cycle efficiency varies less than +/- 2 percentage points over control range (200 to $1000 \mathrm{~W} / \mathrm{m} 2)$. The lab test rig will be built to measure overall turbine-alternator efficiency.

\section{$\underline{\text { Technical Discussion }}$}

The SolarCAT cycle uses variable area turbine nozzles on Stages 1 and 3, and fixed geometry nozzle-less housings with Stages 2 and 4. The part-load analysis of this system was rigorously modeled in Phase 1. In Phase 2 the turbines were tested over their operating ranges, varying nozzle position, as well as temperature, flow, and pressure. The part-load models were updated to reflect the performance expectations developed from the turbine test program. The results of this work are presented in the following paragraphs.

Two efficiency criteria, or definitions, are used to describe the SolarCAT system operating with compressed air energy storage. Treated as a Dish-Brayton, the efficiency parameter is the net electrical power generated divided by the thermal input power. The reference power (denominator) might be that absorbed by the engine or the solar power captured by the dish. For this SOPO, the reference condition was the Brayton cycle input power, delivered by the receiver.

\section{Definition-1:}

$\begin{array}{ll}\text { Engine Cycle Efficiency (Dish Brayton or SolarCAT) } & \text { Eq. } 3\end{array}$

$=\underline{\text { Integrated Electric (AC) energy to the grid - integrated energy compressor energy }}$

\section{Thermal energy absorbed by the engine}

The above definition uses time and pressure integrated energy terms. For the SolarCAT cycle, another efficiency parameter is the instantaneous electrical power generated divided by the instantaneous thermal or solar input power, operating at steady-state conditions.

\section{Definition-2:}

SolarCAT Cycle Efficiency $=\quad$ Electric (AC) power to the grid $\quad$ Eq. 4 Thermal power absorbed by the engine

This is the critical metric for the SolarCAT cycle because of the premium value placed on peak day-time power, while the compressor is not operating. The off-peak energy 
consumed by the compressor occurs during the utility's low demand period, typically between midnight and 6 am. Further complicating the definition is that the compressor energy consumed must be integrated over time and the changing pressure in the storage vessel. These conditions are rigorously modeled for the specific storage cavern and the 4-stage centrifugal when calculating the LCOE, but not included in this section.

Phase 2 proceeded to build and test the SolarCAT components for eventual integration with a compressed air energy storage system. In Phase 2, both efficiency metrics are recalculated. Figure 2.4 shows the Definition- 1 efficiency for a hypothetical case where the turbo-alternator is operating at the same air flow rate as that produced by the compressor. For this case study, the analysis assumes that the system operates at a constant pressure over the entire DNI range. The model assumes the pressure losses associated with the transport of air in and out of the storage cavern and piping network. .

Figure 2.4 presents the SolarCAT efficiency with and without the inclusion of the receiver and dish losses. The system efficiency, including receiver and dish losses is represented by the green line. The engine alone efficiency (Definition-1) is shown as the red line. To assess the sensitivity of turbine efficiency, a worst-case assumption is shown as the open symbols. The projection varies from $34 \%(1000 \mathrm{~W} / \mathrm{m} 2=117 \%$ of normalized $850 \mathrm{~W} / \mathrm{m} 2$ design point) to about $29 \%$ (at $200 \mathrm{~W} / \mathrm{m} 2=24 \% \mathrm{DNI}$ ), with a mid range peak of about $36 \%$.

Electrical Efficiency

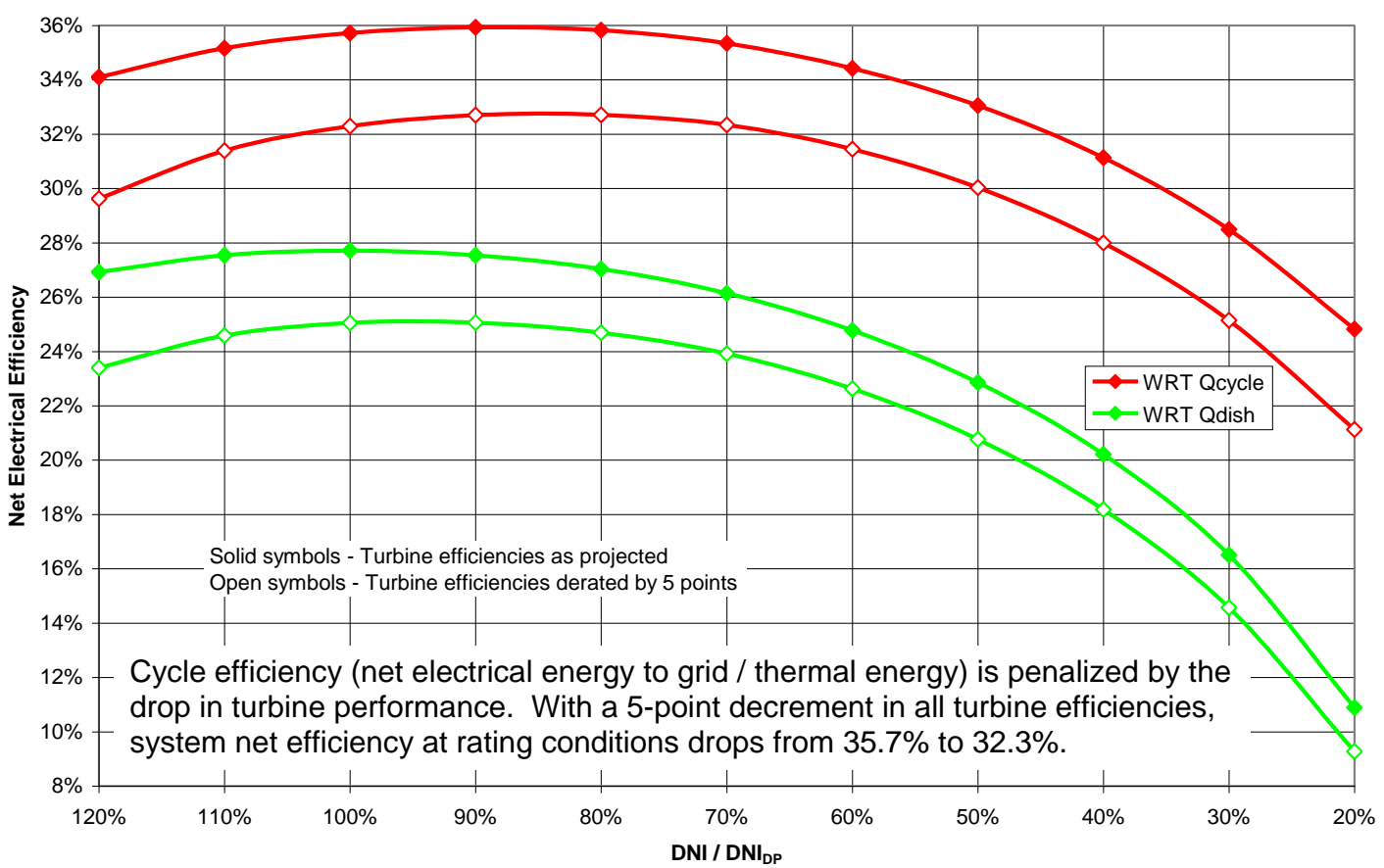

Figure 2.4 Analysis of cycle efficiency with respect to engine input thermal (red line) and dish solar input (green line). The DNI reference design point is $850 \mathrm{~W} / \mathrm{m} 2$. The closed symbols represent the prediction based on the Phase 1 analysis, while the open symbols 
represent the performance assuming a decrement of 5 percentage points for all four turbines. This extreme scenario is assumed to bracket the worst-case possibility, roughly constant with our early state of development.

The SolarCAT efficiency (Definition -2) is provided in Figure 2.5. Over the range of interest, this parameter varies from $87.1 \%$ to $83.1 \%$ for the prediction based on Phase 1 turbine efficiency predictions, or $86.7 \%$ to $82.7 \%$ for the system when incorporating the 5 point turbine decrements.

Ratio of Gross Electrical Power to Cycle Thermal Input

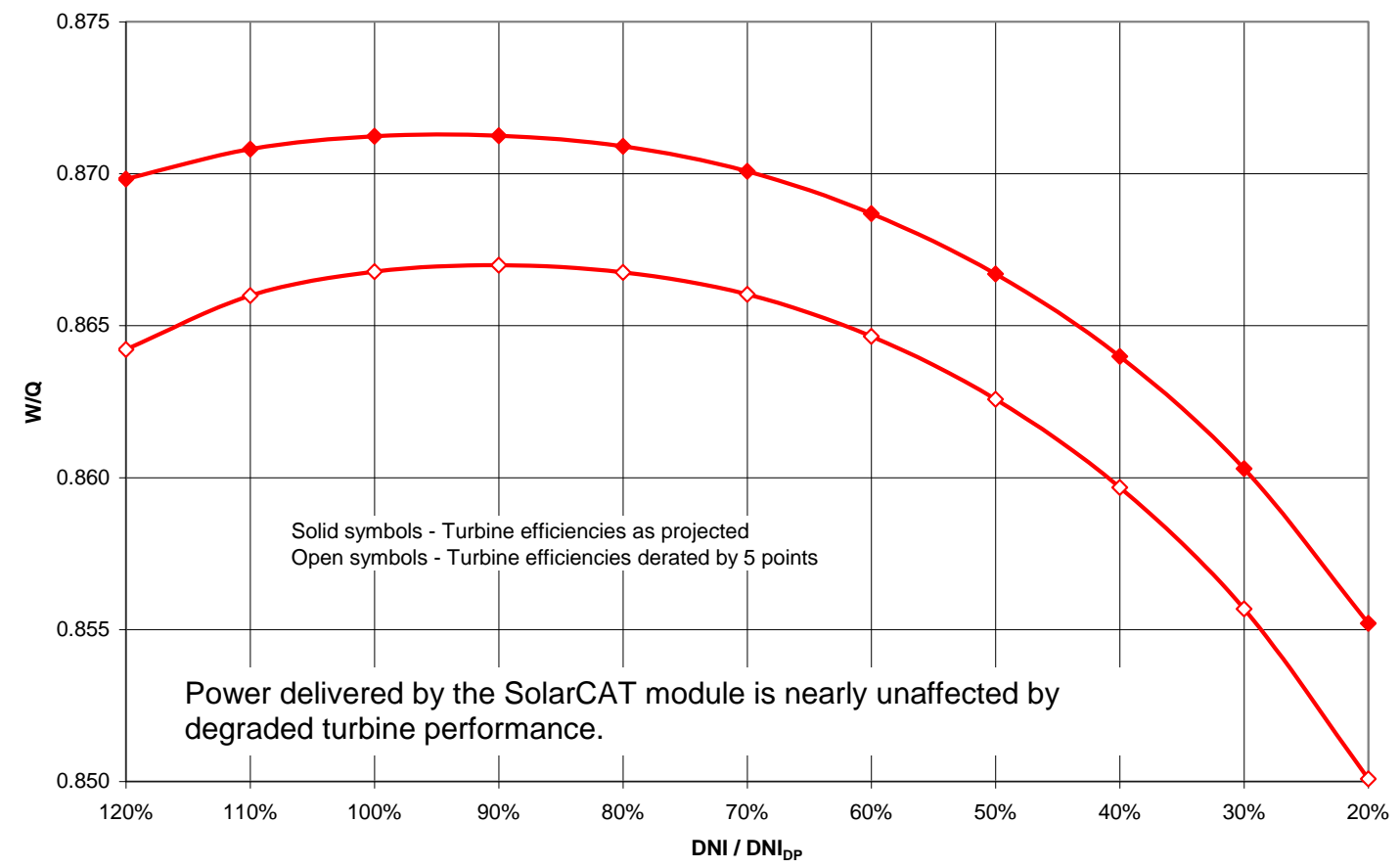

Figure 2.5 SolarCAT cycle efficiency parameter: the ratio of electric power delivered to the grid to thermal input. The engine cycle efficiency is referenced to the energy entering the engine (red line) while the system efficiency is referenced to the solar energy entering the dish aperture (green line). The closed symbols are indicative of the mature performance predicted in Phase-1, while the open symbols represent the performance with a five efficiency-point decrement to each turbine.

Conclusion: As dictated by the SOPO, a rigorous analysis of the proposed system's part-load performance was performed. The modeling was performed with both analytical and decremented turbine efficiency values to bracket the impact on efficiency anticipated from laboratory measurements. The SolarCAT efficiency parameter varied much less than the $+/-2$ pct (4 point spread) targeted in the SOPO, even when including a 5 pct decrement in overall turbine efficiency. 


\subsection{Demonstrate overall turbo-alternator integrity in short-term testing.}

SOPO: The objective of this task is to demonstrated overall integrity of the turbine and hot section. After testing for nominally 50 hours, inspection will be performed to check for material distress. Also the avoidance of VAN galling caused by thermal distortion is a key objective.

Testing was conducted over a roughly 20 month period, starting in October 2009. The 50-hour inspection was met in May 2010. Up to that point no failures or degradation in the turbines, alternator, or bearings was observed. At that stage Brayton received a set of redesigned alternators, with cost reduction features. Soon after testing resumed a series of four system failures occurred. A comprehensive root-cause analysis program was conducted through January 2011. Several quality-related issues associated with the design of the rotor, stator, balancing, and assembly were identified as potential problems and changes were implemented to substantially improve the design and manufacturing procedures. One of the most significant factors contributing to premature failure relates to the inconsistency of the starting method. It was discovered that the air bearings require a very high acceleration rate during starting. It is imperative to accelerate through the foil lift-off speed and the rigid body shaft-dynamic modes which reside well below the operating range. Ultimately the problems were solved by controlling the alternator load and air delivery during the start sequence.

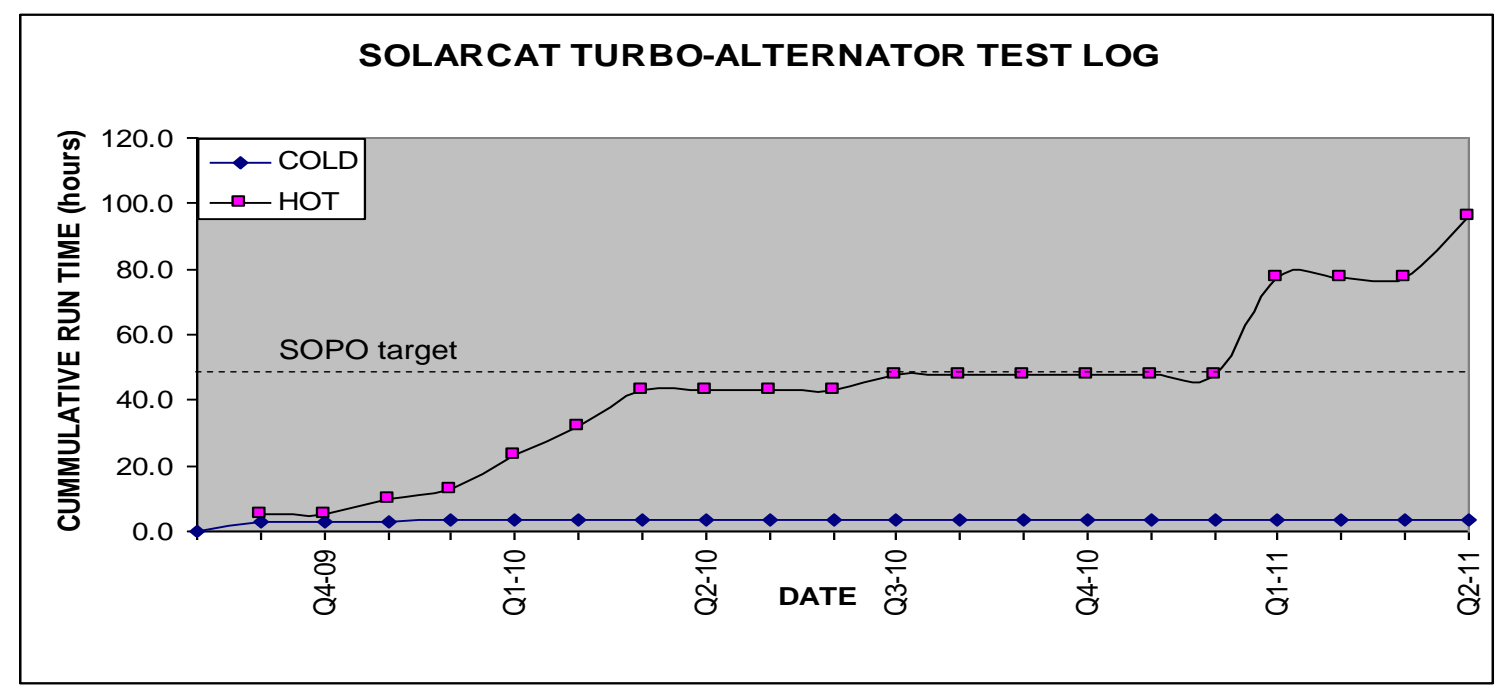

Table 2.5 Turbine testing run-log. A tare-down and through mechanical review was made at the SOPO target of 50 hours. Following testing added another 50 hours to the log.

Conclusion: Approximately 100 cumulative hours of operation were conducted in Phase 2 - roughly twice the requisite amount. The testing was conducted over the entire power range of the alternator. 


\subsection{Define receiver manufacturing methods and cost}

SOPO: The objective of this task is to perform manufacturing trials to qualify tube bending and joining procedures. This work will lead to a defensible cost estimate for the solar receiver.

\section{Technical Discussion}

Over the course of Phase 2, Brayton devoted much effort to the fabrication of the Alpha tubular receiver. Two units were formed by hand on a mandrel, while a parallel fully automated numerically controlled (NC) tube bender was evaluated. After reviewing the $\mathrm{NC}$ tube bender products of several qualified suppliers, the trial experiments were performed at SMT Industries in Ohio. This experience proved that the NC bending operation can produce a part of adequate precision in less than a one-minute cycle time. Several iterations involving many trials, and the subsequent evaluation of the shape errors led to a good understanding of the spring-back issues. Early in the process, repeatability was not meeting QA targets; however that was corrected by properly specifying and controlling the annealed state of the raw tubing.

The Alpha tubular receiver cost models uses the complete BOM, manufacturer quotes, and assembly experience gained at SMT Industries. A preliminary cost analysis of the plate-fin receiver indicates that there is a significant cost savings in raw materials, but this gain is off-set by additional labor. Since the fabrication of the plate-fin cells for the Beta receiver would use the same major capital as the recuperator (brazing and welding), the labor may be reduced by better utilization of the equipment and personnel and some light assembly automation. Given the various factors, preliminary cost estimates indicate a roughly $10 \%$ to $20 \%$ cost savings relative to the Alpha receiver. Table 2.6 provides the comparison of cost and physical metrics. Details on the Alpha and Beta receivers are provided in the Appendices.

$\begin{array}{ll}\text { Shape } & \begin{array}{l}\text { Alpha, Bent Tube } \\ \text { Conical }\end{array} \\ \text { Diameter } & 1.22 \mathrm{~m}\left(48^{\prime \prime}\right) \\ \text { Height } & 1.22 \mathrm{~m}(48 ”) \\ \text { Weight, absorber } & 114 \mathrm{~kg} \\ \text { Est. Life (hrs) } & \text { IN601: 29.5k } \\ \text { Peak Temp } & 1250 \mathrm{~K} \\ \text { Material Cost } & \$ 8,550 \\ \text { Cost target (at 500/year) } & \$ 29,000\end{array}$

Table 2.6 Results of receiver manufacturing studies. 
Conclusion: Extensive manufacturing studies, combined with detailed thermal, stress, and life analyses were performed during the completion of this SOPO task. Two viable designs were generated, for which detailed manufacturing cost evaluations were performed. The overall cost of the baseline tubular receiver was found to be about $28 \%$ higher than that estimated in Phase 1 ( $\$ 22,000$ vs $\$ 29,000)$. A lower cost plate-fin alternative is proposed for further review in Phase 3.

\subsection{Dish Review, Characterization and Testing}

SOPO: The objective of this task is to support the design of the solar concentrator (dish) and its integration with the solar receiver. This task includes the following;

1. Brayton will host two dish design reviews for the National Laboratories (one before testing and one after testing)

2. Develop test plan for receiver and dish (these test plans will be provided to the National Laboratories for comment and suggestions)

3. Perform characterization testing of new prototype SolarCAT dish. The National Laboratories will be given the opportunity to support and observe the characterization and testing of this dish.

The National Laboratories (SNLA and NREL) will be given the opportunity to review and provide comment and suggestions on preliminary and final component and system designs and integration and test plans for individual components, receiver, engine, solar dish concentrator and complete system. Brayton will provide to the National Laboratories with design information and documents at monthly meetings. A representative of the dish design team will attend these meetings and provide updates on the progress of the dish development. It is expected that the National Laboratories will review and give supporting recommendation, if necessary, in the design of component and system tests including; test objectives and design, instrumentation requirements, data collection and evaluation.

\section{Technical Discussion}

The complete functional dish was designed, fabricated, and tested with no federal funding (figure 2.6). Brayton and Southwest Solar Technology collaborated on the test plan and its execution. NREL and SNLA reviewed the test plans and provided useful direction. NREL performed valuable facet characterization studies. A summary of specifications and achievements follows:

- Dish aperture - nominally 319 sq meters, representing the largest US dish ever built. Israeli and Australian dishes hold the record with apertures in the 400 to 500 sq meter range.

- The pedestal design has azimuth - elevation tracking.

- The facet construction yielded excellent mirror quality, with slope errors in the range under $1 \mathrm{mrad}$. 
- Due to the prototypical nature of this dish, some gross mirror distortion problems occurred, mainly attributable to shipping and prolonged storage.

- The overall geometric concentration ratio specification of 1800 (aperture diameter of $46.7 \mathrm{~cm}$ or 18.4 inches) was tested. Due to some of the deficient facets, spillage was higher than planned, 5 to $10 \%$. By masking the worst facets, the spillage was more reasonable at about 2 to $3 \%$.

- A special purpose cavity flux mapping system was developed by SST, which was used to obtain quantitative flux map of the interior surfaces of the cavity and the aperture plans.

- Brayton built and delivered on the program a special purpose cold-water calorimeter. This was used to measure the overall power delivered form the dish and obtain some intercept factor data at the aperture.

- Due to some relaxation of several facts, these mirrors had longer focal lengths than intended. This was a contributor to the very 'peaky' flux distribution incident on the solar absorber.

Conclusion : The obligations of the SOPO task have been met in the fabrication and test of the SST dish. This dish serves as a viable engineering tool for Phase 2 and Phase 3 testing. In addition to the field testing, SST also performed wind-loading studies on a sub-scale model in a wind-tunnel at Texas A\&M. These studies, combined with CFD modeling and the full-scale structural testing have made a significant contribution to the understanding of large parabolic dishes. Finally, the design of a second generation dish which appears to meet the aggressive program cost of $\$ 250 / \mathrm{m} 2$ is on-going and will be presented in Phase 3. 


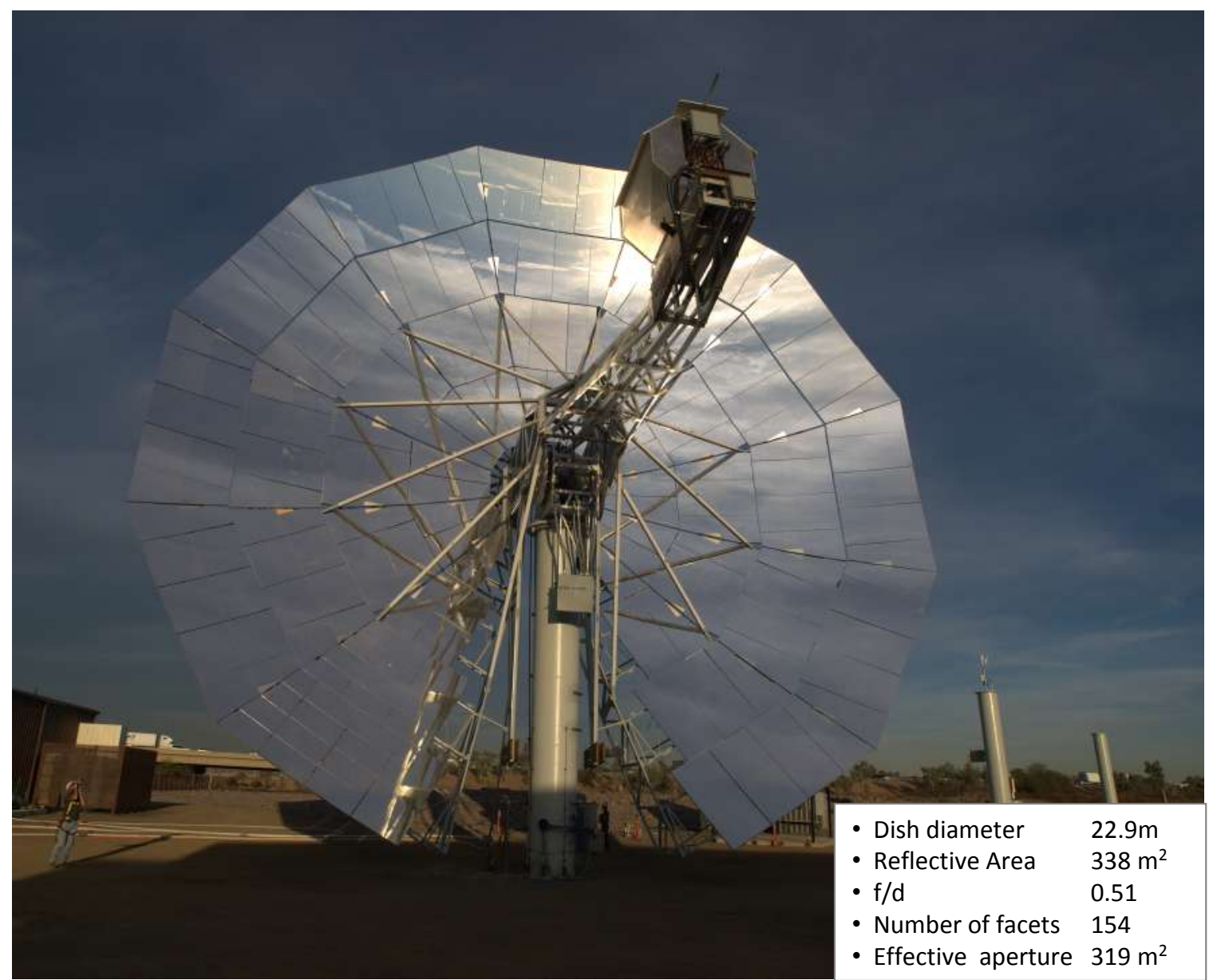

Figure 2.6 The SST Dish-1 serves as the test bed for SolarCAT and Dish-Brayton demonstration systems. The development experience has led the team to an improved understanding of large dishes and their costs. This work is being incorporated into the new Dish-2, which is believed to achieve a cost of nominally of $\$ 80,000\left(\$ 250 / \mathbf{m}^{2}\right)$.

\subsection{Characterize solar receiver performance}

SOPO: The objective if this task is to correlate heat transfer and pressure loss models with test results, leading to final receiver design. A receiver will be fabricated and delivered to the concentrator test facility for on-sun testing. The testing, in accordance to the plan developed in Task 2.6, will be performed with cold compressed air and some form of a preheater. The solar receiver efficiency goal is $>86 \%$ at projected gas inlet and exit temperatures, based upon a geometric dish/aperture concentration ratio of 1800.

\section{Technical Discussion}

Brayton incorporated the first generation receiver into an operationally-flexible test rig, shown figure 2.7. The test unit is able to adjust temperature, pressure, and flow rates for both HP and LP sides of the receiver; ensuring that the test points can be met. 

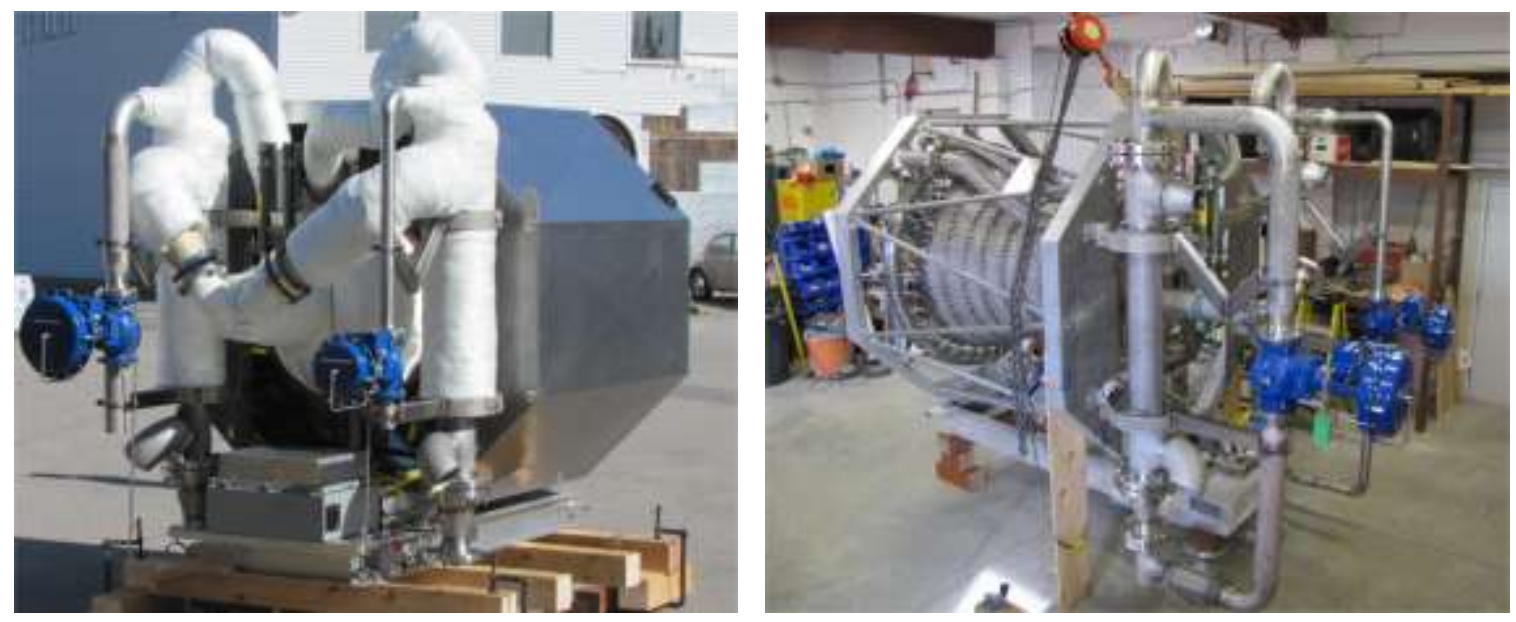

Figure 2.7 Photograph of solar receiver test rig during final assembly.

The high-level sensors and control variables are illustrated in figure 2.8.

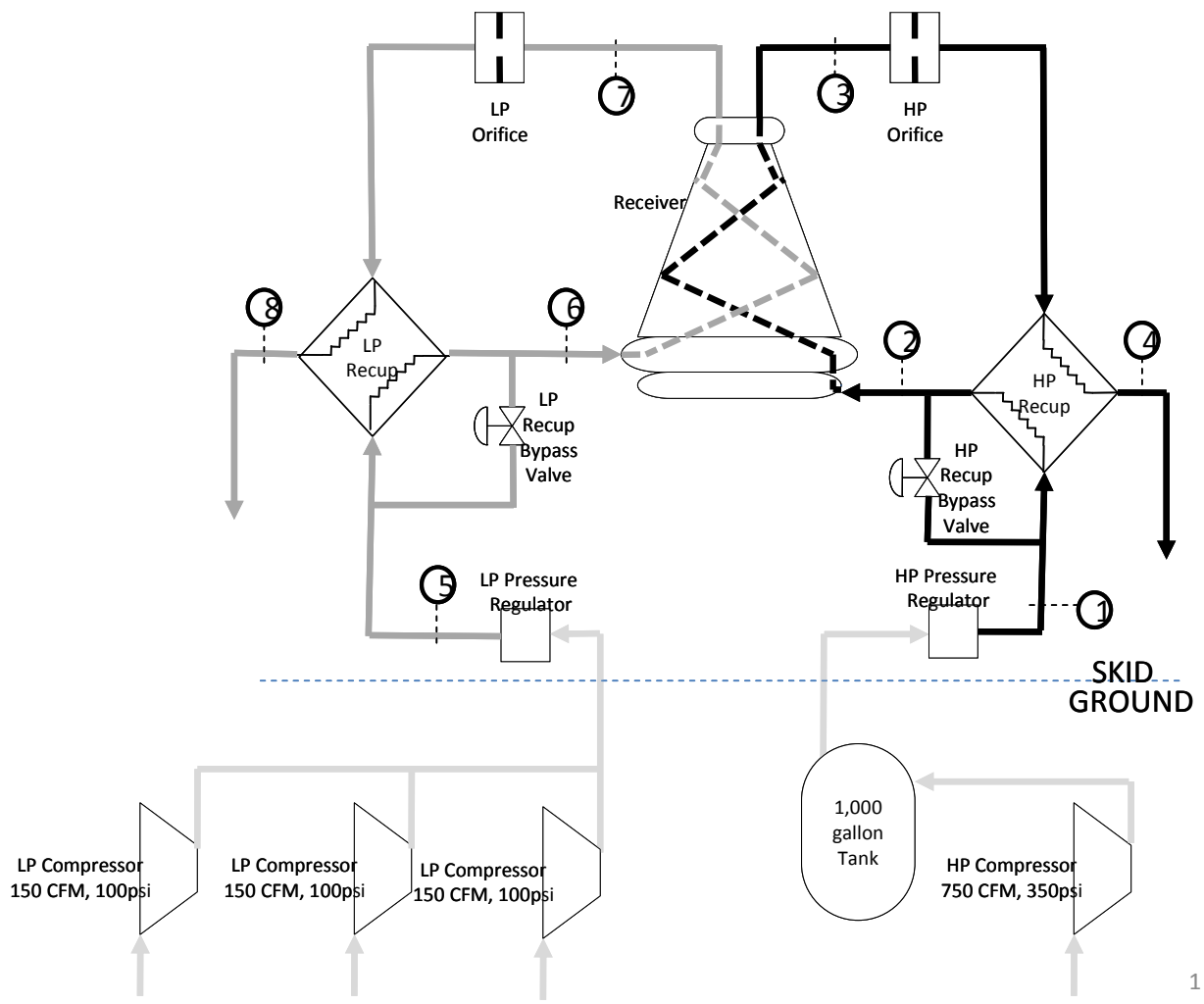

Figure 2.8 High-level schematic representation of the receiver test rig employed in the SST Dish 2.

The initial dish alignment followed an approach of pointing each mirror at the center of the aperture. After mapping the flux profile on the absorber, severe flux distribution anomalies were observed. The peak flux exceeded tolerable levels at several locations. Using the resulting receiver flux maps as guides, individual mirror facets were systematically re-aimed to minimize spillage around the aperture, reduce localized flux peaks on the receiver tubes, and improve overall power distribution around the receiver 
circumference. Despite repeated mappings and mirror adjustments, the best flux pattern that was achieved from the dish showed peaks well above the levels for which the receiver was analyzed $\left(20 \mathrm{~W} / \mathrm{cm}^{2}\right)$. The best case flux map that was measured had a localized peak flux $=34 \mathrm{~W} / \mathrm{cm}^{2}$. Thermal analysis models indicated that this would yield wall temperatures over the $1300 \mathrm{~K}$ limit of the stainless steel test article. Correcting the most distorted facets remains a key objective of Phase 3. SST is prepared to make the facet and alignment improvements.

In light of the ongoing efforts to correct the flux distribution issues, strategies to enable safe receiver testing to proceed were reviewed with the NREL and Sandia technical experts. The favored approach covers the dish with a light-attenuating shade to lower the overall flux levels. The calorimeter was used to characterize the properties of a shade material recommended by NREL. The receiver air flow rate was adjusted to achieve the design-point inlet and outlet temperatures. This enables the receiver losses to be accurately measured over the range of operating conditions.

The receiver was commissioned and tested according to the Receiver Test Plan. In a series of day-long tests, the receiver temperature was incrementally increased by reducing air mass flow and controlling the temperature of the preheated receiver inlet air with discretely adjustable bypass valves. A total of approximately 50 hours of on-sun operation was achieved without the quartz window installed at the aperture in order to allow for easy post-test visual inspection of the receiver cavity. After tubes were fully oxidized, the quartz window was installed at the aperture, and the receiver was brought to full operating temperature to measure receiver efficiency. The target conditions for rated power were:

- Low pressure side inlet temp $=850 \mathrm{~K}\left(575^{\circ} \mathrm{C}\right)$

- High pressure side inlet temp $=883 \mathrm{~K}\left(610^{\circ} \mathrm{C}\right)$

- Outlet temp for both sides $=1200 \mathrm{~K}\left(927^{\circ} \mathrm{C}\right)$

Figure 2.9 presents measured receiver efficiency as a function of receiver tilt angle, plotted alongside predictions made from laboratory heat loss experimental data. Table 2.8 presents measured dish powers and losses from which the receiver efficiencies were derived. 


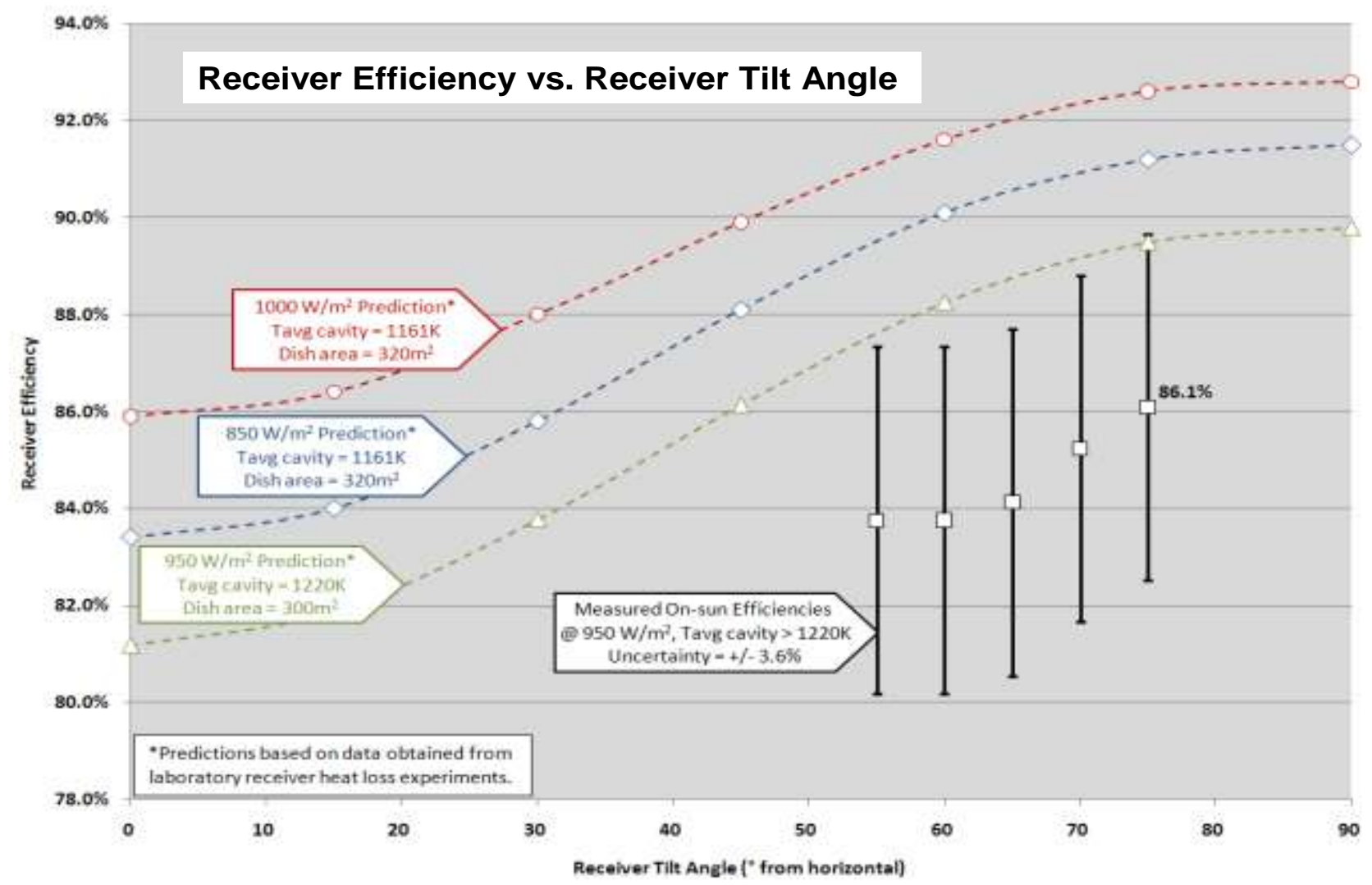

Figure 2.9- Measurements are shown with the error bars. The dashed lines are predictions made from the laboratory heat loss rig.

\begin{tabular}{|c|c|c|c|c|c|c|c|c|}
\hline 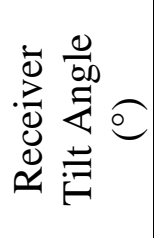 & $\bar{a} \frac{\pi}{\xi}$ & 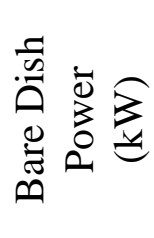 & 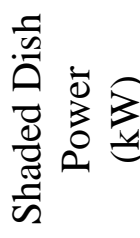 & 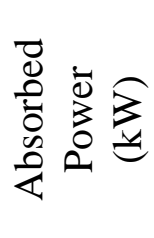 & 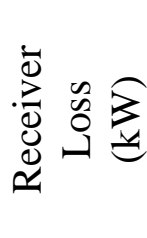 & 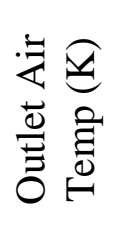 & 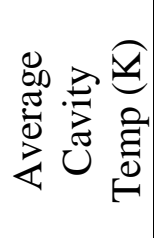 & 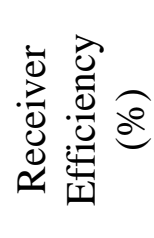 \\
\hline 75 & 963.8 & 245.0 & 51.7 & 17.6 & 34.1 & 1185 & $>1212$ & $86.1 \%$ \\
\hline 70 & 963.9 & 245.0 & 51.7 & 15.5 & 36.2 & 1189 & $>1211$ & $85.2 \%$ \\
\hline 65 & 959.6 & 243.9 & 51.4 & 12.7 & 38.7 & 1192 & $>1217$ & $84.1 \%$ \\
\hline 60 & 947.3 & 240.8 & 50.8 & 11.7 & 39.1 & 1196 & $>1220$ & $83.8 \%$ \\
\hline 55 & 927.5 & 235.7 & 49.7 & 11.4 & 38.3 & 1199 & $>1221$ & $83.8 \%$ \\
\hline
\end{tabular}

Table 2.8 - Receiver Power and Efficiency Data

In Table 2.8, the referenced 'Average Cavity Temperature' is a metric which relates to the cavity radiation loss. The averaging method is defined below.

$$
T_{\text {avg }}=\left\{\sum_{n}^{i=1}\left[F v * T_{i}^{4}\right] / n\right\}^{1 / 4}
$$


Where the average cavity radiating temperature $=\mathbf{T}_{\text {avg }}$ The local geometric view factor between the location of the temperature measurement to the receiver aperture $=\mathbf{F v}$

The local absorber surface temperature $=\mathbf{T i}$

The number of measurements $=\mathbf{n}(=36)$

Analytical heat transfer models combined with our solar ray-tracing model predicted an average cavity temperature $\left(T_{\text {avg }}\right)$ of approximately $1160 \mathrm{~K}$ at design conditions. An indication of the actual cavity temperature was derived from thermocouples affixed to the backs of 36 tubes on the solar absorber. Using an FEA-based correction factor, the average absorber temperature was estimated, and included in Table 2.9. The reported values were in the range of $1220 \mathrm{~K}$ are believed to be attributable to the poor flux cavity distribution. The higher-than-expected receiver temperatures contributed to the short-fall in receiver efficiency.

While the SOPO target of $86 \%$ receiver efficiency was achieved, it is recognized that there were a number of sources of excess heat loss which were present in these early experiments. These are discussed in the following paragraphs.

Heat damage to instrumentation wiring that was experienced during early stage testing. This required the removal of insulation from a significant portion of the receiver, to prevent serious damage to the control and DAS system wiring. This lack of surrounding insulation and enclosure panels allowed outer insulation temperatures to reach $400 \mathrm{~K}$ while being exposed directly to winds measured at steady values of $4-14 \mathrm{mph}$. Furthermore, operation with the enclosure removed allowed hot air, normally trapped within the cavity volume, to percolate through the insulation.

At this stage of our development, wind variability has not been factored into receiver analysis models. Though wind speed and direction is measured and recorded during the testing, acquiring consistent conditions with moderate wind speed represented a logistical challenge which delayed testing. At this early stage of model validation, it was desirable to operate with speeds under $5 \mathrm{mph}$. As mentioned above, the test data reported was gathered over a wider than desirable wind speed range of 4 to $14 \mathrm{mph}$. It should be noted that the June test window was on the cusp of monsoon season in Phoenix, accounting for very unsettled atmospheric conditions. Over the course of testing, wind gusts up to 66 were recorded at the airport 5 miles from the dish.

A vendor error lead to production of a quartz window composed of tubes with an aspect ratio of 2 (length / diameter) instead of the intended figure of 3. The shorter tubes resulted in a radiation loss increase estimated to be on the order of $1 \%$.

Table 2.9 summarizes the effect that each of the aforementioned deficiencies experienced with the receiver test. Correction of these problems in Phase 3 should push the receiver efficiency up to levels predicted by models validated in the earlier laboratory tests. 


\begin{tabular}{|l|l|c|}
\hline \multicolumn{1}{|c|}{ Loss Factor } & \multicolumn{1}{|c|}{ Mitigation } & $\begin{array}{c}\text { Estimated Efficiency } \\
\text { Improvement }\end{array}$ \\
\hline $\begin{array}{l}\text { Elevated cavity wall } \\
\text { temperatures }\end{array}$ & $\begin{array}{l}\text { Improve dish to level flux } \\
\text { distribution on the absorber }\end{array}$ & $1 \%$ \\
\hline $\begin{array}{l}\text { Surrounding insulation / } \\
\text { enclosure panels removed to } \\
\text { protect instrumentation }\end{array}$ & $\begin{array}{l}\text { Upgrade to high temp wiring, } \\
\text { insulate enclosure, install } \\
\text { panels }\end{array}$ & $2-3 \%$ \\
\hline Windy test conditions & Test during calm day & $1 \%$ \\
\hline $\begin{array}{l}\text { Quartz window manufacturing } \\
\text { error resulted in 2:1 aspect } \\
\text { ratio quartz tubes }\end{array}$ & $\begin{array}{l}\text { Replace with 3:1 aspect ratio } \\
\text { quartz tubes, reducing } \\
\text { radiation losses }\end{array}$ & $1 \%$ \\
\hline $\begin{array}{l}\text { Insufficient insulation of } \\
\text { outlet manifolds, heat loss }\end{array}$ & $\begin{array}{l}\text { Improve outlet manifold } \\
\text { insulation scheme }\end{array}$ \\
\hline
\end{tabular}

Table 2.9 Table of receiver improvement opportunities and rough projections of their relative impact.

Conclusion: Like other SOPO's, an aggressive performance target was set for this task. Receiver testing, both on the dish and in the laboratory, provided a solid understanding of the receiver loss mechanisms. Despite several correctable deficiencies discovered in the design and sever flux anomalies within the cavity, on-sun testing demonstrated an efficiency above the SOPO target of $86 \%$ at rated conditions. Additionally this benchmark was achieved at higher that average wind speeds.

\section{$2.8 \quad$ Project Management and Reporting}

SOPO: Reports and other deliverables will be provided in accordance with the Federal Assistance Reporting Checklist following the instructions included therein.

The following management-related deliverables were provided on time for each reporting period:

- A monthly report and presentation was delivered on the first Tuesday of each month over the entire course of the program. DOE and lab representatives were notified and good attendance and participation from the Golden Office, SNLA, NREL, and DOE-HQ monitors was appreciated by the Brayton and SST staffs.

- Quarterly written reports and financial reports were uploaded to the Fed-connect site for each period.

- Two on-site meetings were held at the dish test site in Phoenix.

Conclusion: The project management objectives of the program were met on a timely basis and were performed in accordance with Federal Acquisition Regulations (FAR). 


\subsection{Conclusions and Recommendations}

This program was discontinued after Phase 2, preventing the overall test of the complete system. The complete power conversion system was delivered to the solar dish test site in Phoenix AZ.

Over the course of the development, many improvements were identified. Improvements to the receiver, dish, and turbo-alternator were mentioned in the proceeding sections, but for the most-part, the discussion of SOPOs was focused on the hardware that was built and tested. The most significant design change recommendation relates to the general architecture of the multi-spool power conversion system. The program was initiated with a $50 \mathrm{kWe}$ alternator design because of its early availability without significant engineering and cost. A $100 \mathrm{kWe}$ alternator is now available, operable at nominally the same speed. This suggests that the two pairs of $50 \mathrm{kWe}$ turbo-alternators may be combined into a just two $100 \mathrm{kWe}$ spools. That is, Stage $1 \& 2$ becomes a single HP spool while stages $3 \& 4$ become the LP spool. In that case, the expansion ratio of each turbine rotor increases from 2.1 to about 4.5. The temperature and tip speed for this design is nearly identical to that of today's microturbines, so stress and life should not be major challenges. The two-spool arrangement and current 4-spool are shown schematically in Figure 2.10 for comparison.
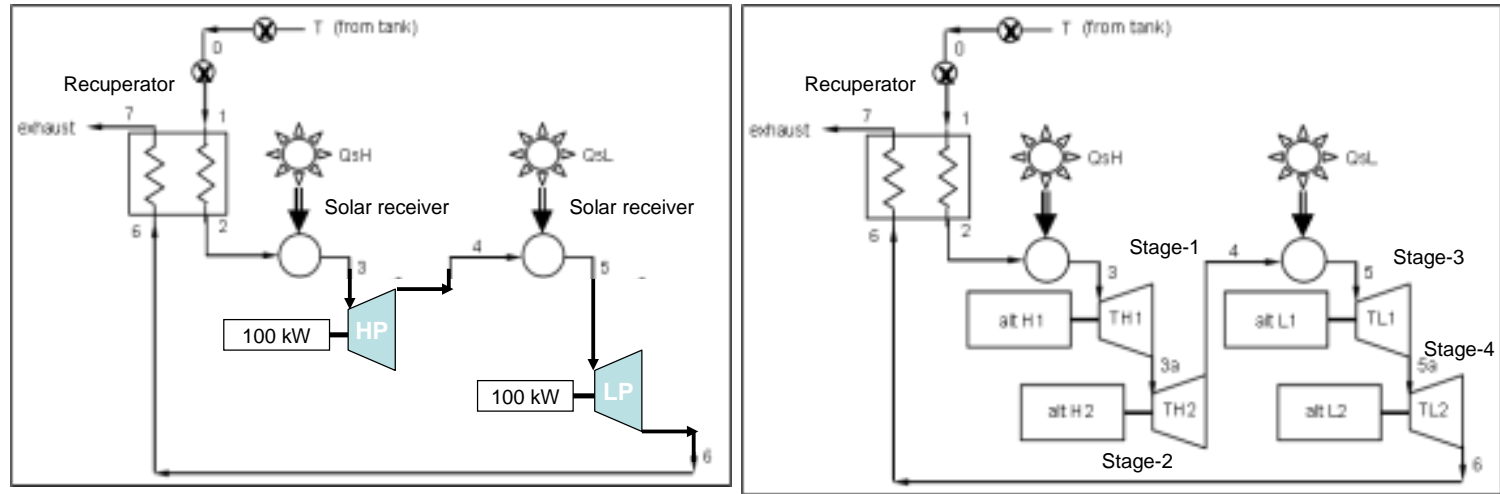

Figure 2.10 Schematic comparison of 2-spool and current 4-spool is shown.

Brayton completed the integrated design work for the complete power conversion on Phase 2 and proceeded to build critical-path portions of the system on Phase 3. This included the fabrication of the recuperator, the engine's thermal-mechanical support structure, and the overall enclosure. No problems were encountered during the assembly.

\section{Summary of Final System Cost Models}

During the second dish review meeting (Feb 23, 2011), a technical design review was provided on all Phase- 2 components. This presentation displayed the turbo-alternators, receiver, and other components for inspection and also provided detailed cost projections for the complete bill of materials. Table 2.10 summarizes the costs of the major subassemblies, comparing the results against the previous estimates made in Phase-1. 


\begin{tabular}{|l|r|r|r|r|r|}
\hline & & \multicolumn{2}{c|}{$\begin{array}{c}\text { 500 unit lot (using } \\
\text { Morton storage) SAI } \\
\text { Phase-1 }\end{array}$} & \multicolumn{2}{|c|}{$\begin{array}{c}\text { 500 unit lot (using } \\
\text { Morton storage) SAI } \\
\text { Phase-2 }\end{array}$} \\
\hline \multicolumn{1}{|c|}{ Summary, Capital, \$ } & units & Solar-only & Hybrid & Solar-only & Hybrid \\
\hline Dish, installed & $\$$ & 76,160 & 76,160 & 76,160 & 76,160 \\
\hline Solar receiver/hybrid combustor & $\$$ & 21,760 & 23,760 & 27,839 & 29,839 \\
\hline Turbomachinery & $\$$ & 29,864 & 29,864 & 26,208 & 26,208 \\
\hline Recuperator & $\$$ & 5,647 & 5,647 & 5,647 & 5,647 \\
\hline Air compressor, w/ coolers and installation & $\$$ & 28,474 & 28,474 & 28,474 & 28,474 \\
\hline Inverter/power electronics/controls & $\$$ & 20,565 & 20,565 & 20,565 & 20,565 \\
\hline Installation, contingency & $\$$ & 17,000 & 17,000 & 17,000 & 17,000 \\
\hline Total Capital Cost, Installed & $\$$ & 199,469 & 201,469 & 201,892 & 203,892 \\
\hline Peak Power, (950 W/m2) or fuel assist) & $\mathrm{kW}$ & 206 & 206 & 206 & 206 \\
\hline Normalized cost, & $\$ / \mathrm{kWp}$ & 970 & 980 & 982 & 991 \\
\hline
\end{tabular}

Table 2.10 Summary cost roll-up of Brayton SolarCAT module and its installation. Additional balance of plant, including piping and cavern costs are included in the LCOE model.

The Brayton Solar Power Conversion System is unique in that its business plan and economic case studies are focused on the deployment of a specific $100 \mathrm{MWe}$ demonstrator plant in Glendale AZ (abutting Phoenix). Since the inception of the program in 2004 under the sponsorship of the Arizona Public Service, Brayton and SST have worked on site preparations to enable the use of one of several large salt caverns produced by the Morton Salt Company in Glendale. The cavern's volume capacity is sufficient to support up to $500 \mathrm{MWe}$. To that end, SST has purchased the surrounding land and initiated site engineering and planning related to the balance of plant. Summary results from the following cost studies have been incorporated into the LCOE:

- Engineering; surveying and planning.

- Site grading and preparations

- Central compressor station and its installation

- Piping and air distribution system

- Enlarging and sealing the bore-hole into the cavern (capacity is $500 \mathrm{MWe}$ )

- Dish pedestal installation

- Electrical network between dishes (local inverters) and the grid interface

- Natural gas boosting and distribution to the hybrid PCU \& dishes.

The LCOE model was constructed using Microsoft Excel with similar cash flow and financing assumptions as the Dish-Stirling case within the NREL solar advisory model (SAM). The model solves for the minimum levelized electricity price that allows for the equity holders to attain a $15 \%$ internal rate of return (IRR) while maintaining a minimum debt service coverage ratio (DSCR) above 1.40. 
The results from the economic case study for Glendale AZ are summarized in Table 2.11. This scenario is relevant to other CAES projects employing geological formation, such as the many sites understudy by EPRI and PG\&E in the US Southwest.

\begin{tabular}{|c|c|c|}
\hline $\begin{array}{l}100 \text { MW Solar-CAES Facility } \\
\text { Morton Cavern Conversion }\end{array}$ & $\begin{array}{l}\text { Solar } \\
\text { Only }\end{array}$ & Hybrid \\
\hline \multicolumn{3}{|l|}{ Capital Costs (\$/kW) } \\
\hline Solar Field Direct Costs & $\$ 1,182$ & $\$ 1,197$ \\
\hline Solar Field Indirect Costs & $\$ 295$ & $\$ 298$ \\
\hline BOP & $\$ 607$ & $\$ 619$ \\
\hline Total Capital Cost (\$/kW) & $\$ 2,084$ & $\$ 2,114$ \\
\hline \multicolumn{3}{|l|}{$10 \%$ ITC } \\
\hline Real LCOE (\$/kWh) & 8.8 & 8.6 \\
\hline Nominal LCOE (c/kWh) & 11.1 & 10.8 \\
\hline \multicolumn{3}{|l|}{$30 \%$ ITC } \\
\hline Real LCOE (c/kWh) & 7.7 & 7.7 \\
\hline Nominal LCOE (c/kWh) & 9.7 & 9.6 \\
\hline
\end{tabular}

Table 2.11 The SolarCAT system meets the project objective of $\$ 0.10$ per $\mathrm{kWh}$ at the initially established requirements including an ITC of $30 \%$. 


\section{Appendix A - SolarCAT General Principles and Energy Budget}

Some fundamental thermodynamic aspects of the SolarCAT cycle are reviewed here as background for the design details to follow.

As mentioned above, the SolarCAT cycle, with air compression and expansion occurring simultaneously, would become that of a gas-turbine engine under continuous operation. The comparison is highlighted in Figure 1, whose values are based on projected performance levels presented later in this report.
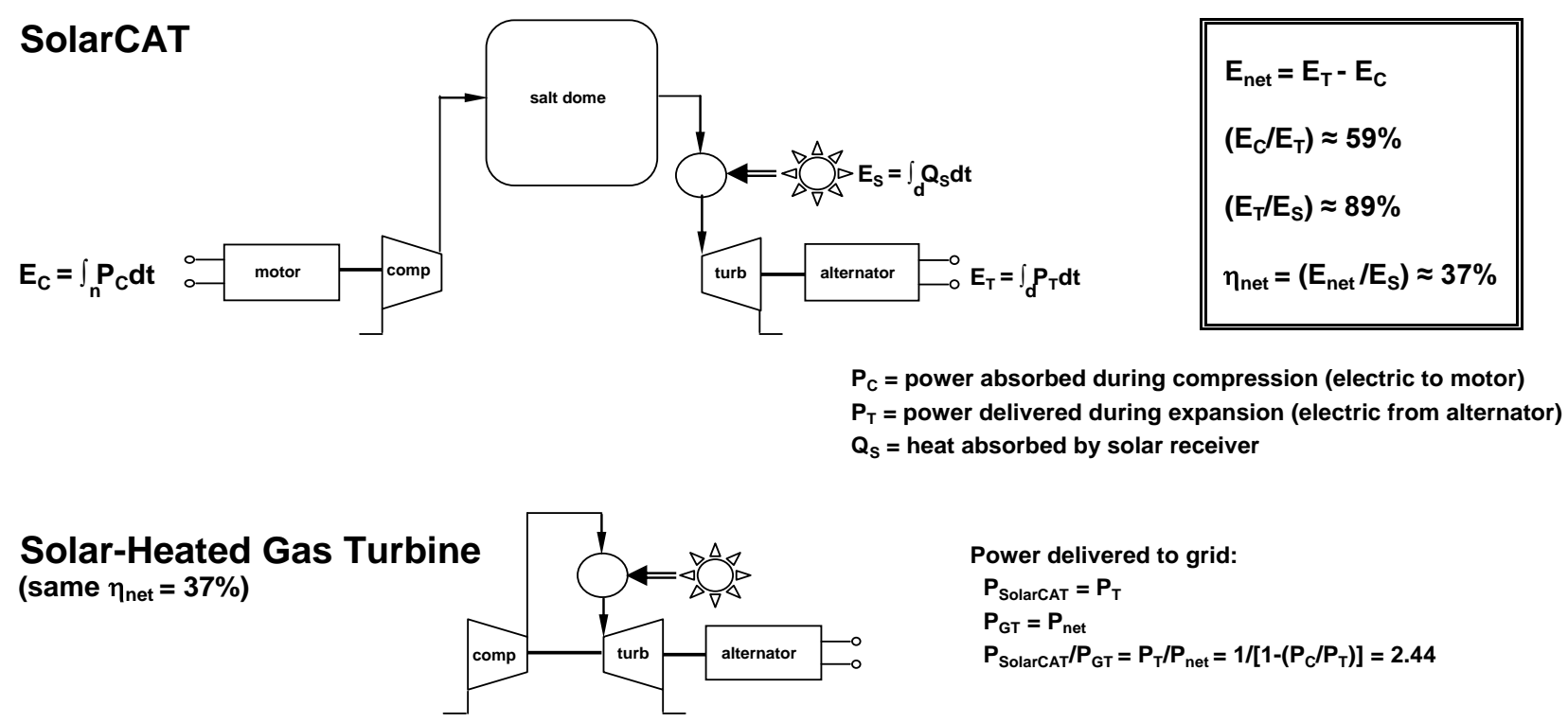

$\longrightarrow$ SolarCAT delivers $\sim 2.4 \mathrm{x}$ more peak power to grid for same collection area

Figure 1. SolarCAT energy budget as compared to a solar-heated gas turbine. In this analogy, Es is the thermal input to the engine cycle. Later in the system analysis, receiver losses are assessed as a fixed power value dependant on cavity temperature while dish losses are represented as fixed efficiency factors (reflectivity and spillage).

As reported in Figure 1, the projected efficiency of the SolarCAT system is around 37\%, this value considered 'representative' (further discussion in the next section of this report). This efficiency is defined as the net electrical energy delivered to the grid divided by the heat input to the cycle. In a conventional gas turbine, the net electrical energy is equal to that produced by the turbine(s) minus that absorbed by the compressor(s), decremented by parasitic losses from bearing and alternator/inverter inefficiency.

SolarCAT's efficiency could alternatively have been defined in terms of solar energy incident on the dish, in favor of thermal input to the cycle. This definition would reflect dish and receiver losses listed in Table 2, resulting in a lower efficiency value. The 
current choice is supported by consistency with conventional gas-turbine practice, wherein heat supplied from fuel combustion is captured entirely within the cycle.

Compared to a gas turbine having the same (37\%) efficiency, a fundamental advantage of the SolarCAT cycle is that substantially more power is delivered to the grid under peakdemand (daylight) operation (roughly by a factor of 2.4). As identified above, this implies much smaller power-generating components, most importantly turbines, for the same rated system output. More importantly, dish area is also reduced in direct proportion.

SolarCAT's high projected efficiency is the product of design focused on multiple fronts. Given that solar energy is sometimes regarded as 'free', the incentive to uphold this value deserves discussion:

- System economics are driven strongly by efficiency, even for pure-solar operation. For the same rated power output, lower efficiency implies higher operating cost from increased power consumption during the compression cycle, and higher capital cost chiefly from the need for increased compressor capacity.

- Hybrid solar/fuel applications are contemplated, for which fuel costs and emissions levels depend directly on system efficiency.

Important factors governing efficiency system efficiency include:

- The vessel pressure. The maximum-efficiency 'optimum' cycle pressure ratio favors lower values than that ultimately specified. Choice of a higher value was motivated by the need to minimize pressure loss through pipe runs to the underground reservoir.

- Turbine-inlet temperature (TIT). Efficiency based on heat absorbed by the SolarCAT cycle favors increased TIT. From the standpoint of incident solar radiation, an offsetting factor is the decline in receiver efficiency stemming from radiation losses.

- The choice of thermodynamic cycle. Substantial efficiency gains are realized by choosing 'intercooled' compression and 'reheat' expansion cycles.

- Turbomachinery component performance. The need to uphold turbine efficiency, while respecting speed limits governed by shaft/bearing dynamics, is the essential factor driving the number of expansion stages.

It is to be noted that reduced dish area (in relation to rated power output) is not offered among the incentives for efficiency gains above. In fact, at least over the allowable range for relevant design parameters, the required dish area remains stubbornly resistant to change by more than a few percent. Component performance compromises, e.g. 
degraded turbomachinery efficiency or increased duct losses, are felt predominantly through the need for increased airflow at prescribed power output, the latter remaining nearly constant in relation to thermal input. The negative impact on cycle efficiency comes chiefly from the gain in compressor work, which is proportional to airflow.

Increased recuperator effectiveness boosts cycle efficiency and power in relation to thermal input, providing an exception to the argument above. Because it allows for reduced dish area at a prescribed power level, the incentive for high recuperator effectiveness is strong. The overall performance specifications and assumptions are provided in Table A1, below. 
Table A1. Component performance specifications used in SolarCAT design-point model. Length of bore hole corresponds to Glendale site. Vessel pressure is chosen to maximize system efficiency at projected $10 \mathrm{MW}$ output, including performance penalty from borehole $\Delta \mathrm{p}$. The stated bore-hole pressure drop incorporates the budgets for the complete air piping network.

\begin{tabular}{|c|c|c|c|}
\hline \multicolumn{4}{|c|}{ Overall Design Performance (100\% DNI) } \\
\hline Module Power $(60 \mathrm{~Hz} \mathrm{AC})$ & \multicolumn{3}{|c|}{$184.4 \mathrm{~kW}$} \\
\hline Net Electrical Efficiency & \multicolumn{3}{|l|}{$37.2 \%$} \\
\hline \multicolumn{4}{|l|}{ Cycle Parameters } \\
\hline turbine-inlet temp & $1200 \mathrm{~K}$ & \multicolumn{2}{|l|}{$(1700 \mathrm{~F})$} \\
\hline vessel pressure & $2206 \mathrm{kPa}$ & \multicolumn{2}{|l|}{ (320psia) } \\
\hline |vessel temp & $288 \mathrm{~K}$ & \multicolumn{2}{|l|}{$(59 F)$} \\
\hline recuperator effectiveness & $94 \%$ & & \\
\hline Turbines & efficiency & \multicolumn{2}{|c|}{ speed(rpm) shaft power $(k W)$} \\
\hline $\mathrm{H} 1$ & $80.4 \%$ & \multicolumn{2}{|c|}{$116000 \quad 55.3$} \\
\hline $\mathrm{H} 2$ & $86.7 \%$ & 100573 & 44.9 \\
\hline |L1 & $87.1 \%$ & 111400 & 55.3 \\
\hline L2 & $85.6 \%$ & 101217 & 44.9 \\
\hline \multicolumn{4}{|l|}{ Compressor } \\
\hline ambient temp & $288 \mathrm{~K}$ & \multicolumn{2}{|l|}{$(59 F)$} \\
\hline number of stages & 4 & \multirow{3}{*}{\multicolumn{2}{|c|}{ (20F) }} \\
\hline stage isentropic effy & $85 \%$ & & \\
\hline intercooler approach temp & $11.1 \mathrm{~K}$ & & \\
\hline intercooler $\Delta \mathrm{p} / \mathrm{p}$ & $2 \%$ & \multicolumn{2}{|l|}{$(20 \mathrm{~F})$} \\
\hline motor effy & $94 \%$ & & \\
\hline \multicolumn{4}{|l|}{ Receiver / Dish } \\
\hline $100 \% \mathrm{DNI}$ & \multicolumn{3}{|l|}{$850 \mathrm{~W} / \mathrm{m}^{2}$} \\
\hline dish area & \multicolumn{3}{|c|}{$307 \mathrm{~m}^{2}$ (mirror) $320 \mathrm{~m}^{2}$ including blockage area } \\
\hline |mirror reflectivity & \multicolumn{3}{|l|}{$90 \%$} \\
\hline blockage & \multicolumn{3}{|l|}{$2.5 \%$} \\
\hline spillage & \multicolumn{3}{|l|}{$2.0 \%$} \\
\hline concentration ratio & \multirow{2}{*}{\multicolumn{3}{|c|}{$\begin{array}{c}1800 \\
0.172 \text { m²}^{2}\end{array}$}} \\
\hline aperture area & & \multirow{2}{*}{\multicolumn{2}{|c|}{$(1619 F)$}} \\
\hline cavity temp & \multicolumn{2}{|c|}{$1155 \mathrm{~K} \quad(1619 \mathrm{~F})$} & \\
\hline receiver loss (kW) & \multicolumn{3}{|l|}{$22.8 \mathrm{~kW}$} \\
\hline cycle heat input & $211 \mathrm{~kW}$ & & \\
\hline Alternator / Power Con & rsion & & \\
\hline bearing efficiency & $98.8 \%$ & & \\
\hline |alternator efficiency & $97.0 \%$ & & \\
\hline rectifier efficiency & $99.0 \%$ & & \\
\hline inverter efficiency & $97.0 \%$ & & \\
\hline Pressure Losses $(\Delta \mathrm{p} / \mathrm{p})$ & & & \\
\hline receiver HP pass & $0.4 \%$ & & \\
\hline receiver LP pass & $5.5 \%$ & & \\
\hline recuperator HP pass & $0.2 \%$ & & \\
\hline recuperator LP pass & $1.6 \%$ & & \\
\hline bore hole & $5.2 \%$ & & \\
\hline
\end{tabular}




\section{Appendix B Phase 1 Mechanical Design of Principal SolarCAT Subassemblies}

The SolarCAT is composed of the following subassemblies

1. Turboalternator: this $53 \mathrm{kWe}$ power conversion module is applied to both SolarCAT and Dish-Brayton products. Four are incorporated in to the SolarCAT, while two are used for the Dish-Brayton. The designers were determined to maintain total interchangeability of the alternators, bearing mechanical assembly and most of the housings. The following components are discussed in this section

a. Turbine section

b. Alternator assembly

c. Bearing system

2. Recuperator: this recuperator operates at modest temperatures, comparable to those of today's microturbines.

3. Solar receiver: This novel heat exchanger is conservatively designed tubular arrangement.

4. Natural gas combustor, to enable hybrid operation.

Additionally, there are ground mounted components,

1. Solar Concentrator: a 300 to $320 \mathrm{~m}^{2}$ parabolic mirror, designed by SolarCAT Inc.

2. Central compressor plant - typically serving 25 to 50 units.

3. Inverter and power electronics -

The majority of the development by Brayton Energy has been devoted to the turboalternator. A new recuperator has also been designed. Though this design builds on proven design and industrial manufacturing principals, it has been improved and optimized for the high-pressure SolarCAT conditions. The tubular solar receiver design builds upon conventional heat exchanger design principals and manufacturing methods. The natural gas combustor employs the well-known fiber burner design, and is ideally suited for this high pressure, high-inlet temperature application. The ongoing dish development is based on new work of APS with their commercial Amonix ${ }^{4}$ tracker system, a $320 \mathrm{~m}^{2}$ concentrating PV array. The dish development is provided in this report.

The top level view of the SolarCAT and Dish-Brayton components is provided in Figure B1 The CAD layout of the Hybrid SolarCAT power conversion system shows the two turboalternator pairs; high-pressure (HP) and low-pressure (LP). Also shown is the recuperator and solar receiver. The design of these subassemblies follows.

\footnotetext{
${ }^{4}$ The Amonix CPV system is a co-development between APS and Amonix Corp. www.amonex.com
} 


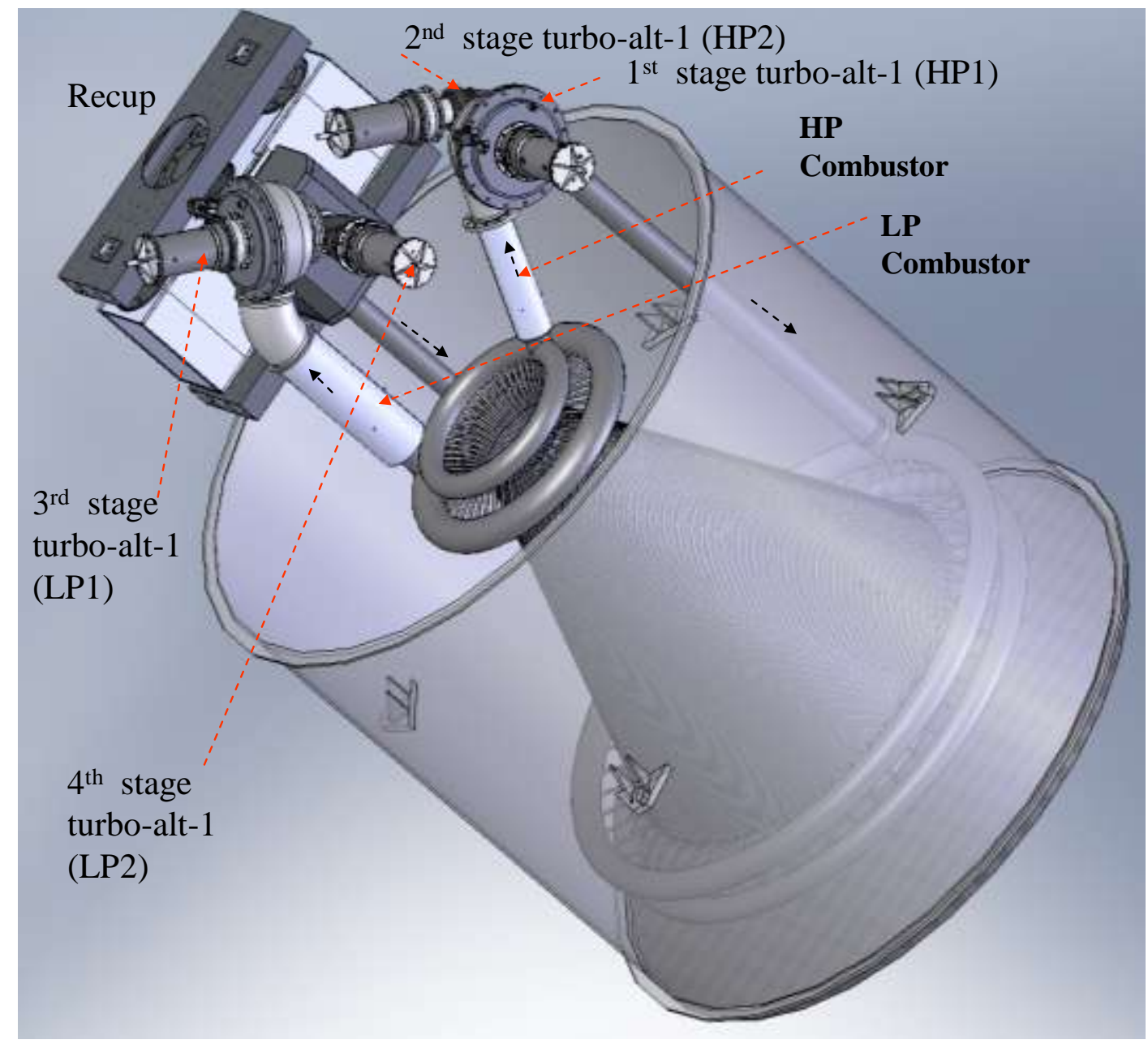

Figure B1 - Top-view of SolarCAT subassemblies..

\subsubsection{Mechanical Specifications}

Table 1 provides a brief description of the power conversion system, and its design life. In all cases the design life is to exceed these minimum life specifications for cycles and endurance. 
Table B1 Life-related specifications for the mechanical subassemblies comprising the power conversion system.

\begin{tabular}{|c|c|c|c|c|}
\hline Assembly & Subassembly & General Description & $\begin{array}{l}\text { Number } \\
\text { of cycles }\end{array}$ & $\begin{array}{l}\text { Life, } \\
\text { hours }\end{array}$ \\
\hline \multicolumn{5}{|c|}{ Turboalternator: } \\
\hline & Turbine rotor & & 8000 & 40000 \\
\hline & Rotor & Investment cast IN713LC alloy (Max Temp 900 C) & & \\
\hline & Shaft & friction welded, steel, case hardened & & \\
\hline & Turbine housings & & 8000 & 40000 \\
\hline & Case/housing & Sand cast Hast-X alloy (Max temp 750 C) & & \\
\hline & Volute & $\begin{array}{l}\text { Sheet metal flow liner (Stages } 1 \& 3 \text { only), Alloy H- } \\
214 \text { Max temp } 927 \text { C. }\end{array}$ & & \\
\hline & \multicolumn{2}{|c|}{ Variable area nozzle assembly } & 8000 & 40000 \\
\hline & VAN & Cast alloy - Max temp $927 \mathrm{C}$ (on Stages $1 \& 3$ only) & & \\
\hline & VAN actuator & stepper motor and linkage & & \\
\hline & Alternator & & & \\
\hline & Rotor & SmCo permanent magnetic & & \\
\hline & Stator & Stamped lamination, air cooled aluminum case, & & \\
\hline & Rectifier & passive diode rectifier & & \\
\hline & Bearing system & & 8000 & 40000 \\
\hline & Bearing core & Cast 300-series stainless & & \\
\hline & Bearings & air foil bearings & & \\
\hline & Coupling & quill type (between PMA and turbine spool & & \\
\hline \multicolumn{5}{|c|}{ Recuperator: } \\
\hline & $\begin{array}{l}\text { Core heat } \\
\text { exchanger }\end{array}$ & $\begin{array}{l}\text { Plate-fin (folded fin - brazed, stamped plate - } \\
\text { welded pressure boundary) (alloy AISI 347) }\end{array}$ & 8000 & 40000 \\
\hline & Case, plenums & sheet metal (alloy AISI 347) & 8000 & 40000 \\
\hline & Support structures & Stainless steel & 8000 & 40000 \\
\hline \multicolumn{5}{|c|}{ Solar receiver: } \\
\hline & Absorber & Tubular, helical (HR-120 alloy) & 8000 & 40000 \\
\hline & Aperture protection & Alumina-silica board (TBD) & 2000 & 10000 \\
\hline & Cavity insulation & Alumina-silica board & 8000 & 40000 \\
\hline & Containment vessel & non-pressure retaining shell, structural support & 8000 & 40000 \\
\hline \multicolumn{5}{|c|}{ Natural gas combustor, } \\
\hline & Igniter & High voltage, low energy & 2000 & 10000 \\
\hline & Fuel injectors, gas & Natural gas tube & 8000 & 40000 \\
\hline & $\begin{array}{l}\text { Fuel injectors, } \\
\text { liquid }\end{array}$ & air blast atomizer & 2000 & 8000 \\
\hline & Burner liner/matrix & Fiber mesh burner (FeCrAlY alloy) & 8000 & 20000 \\
\hline
\end{tabular}

The following sections describe the design of the principal subassemblies.

\subsection{Turboalternator design}


The turboalternator design has been completed and as of August 2008, most of the parts have been released for manufacturing. The design sequence involved several iterations. The trade studies attempted to derive a balance between cost and mechanical complexity, and efficiency. Sparing the reader the details of nearly one year of trials and re-designs, it may be stated that the desire to use air bearings and operate in a subcritical rotor dynamic mode was the dominant factor in the design. Though a 2-spool system appeared feasible, the rotor dynamics and alternator stress levels were pushed into challenging and potentially expensive areas. The second area, involving many redesign iterations was the thermal analysis. Meeting the objective of a passively cooled alternator, and conservative magnetic temperature proved to be challenging. The final design meets all life specifications and technical criteria, emphasizing a reliable design, system economics, low cost. The following studies and analyses were performed, leading to the final design.

- System trade studies: These studies evaluated 2, 3, 4, and 6 stage turbine arrangements in an attempt to derive an optimal balance between turbine efficiency and cost. After an initial evaluation of supercritical bearing systems, the trade studies were constrained to select a final layout capable of operating below the first bending critical speed. To perform these trades, an alternator sizing model was developed to provide preliminary magnetic and rotor dimensions needed to perform the rotor dynamic analysis.

- Dynamic analysis: a detailed rotor dynamics analysis was performed on 2 and 4pole alternators for the two and 4-stage turbine system. The analysis contributed to the final design selection.

- Thrust load analysis were calculated to provide a basis for the bearing design

- Stress and thermal analysis was performed to assure that the alternator magnets were appropriately isolated from the high temperature turbine section

- The detailed air bearings design was performed for final configuration. The final configuration.

- Shaft seals were designed for the final configuration. These seals control the leakage flow from the turbine.

- A detailed alternator design was performed for the final configuration.

After completing the detailed design of the turboalternator, manufacturing drawings were produced and issued for quote to specialized manufacturers. A detailed bill of materials was generated, used to the final cost analysis.

\subsubsection{Turboalternator Mechanical Description}

Each of the four turboalternators utilizes a common mechanical bearing system and alternator. While all of the turbines are designed to be of nearly equal diameter, the turbine ends of each differ slightly for aerodynamic and pressure-containment reasons. Stages 1 and 3 incorporate variable geometry turbine nozzles, while stages 2 and 4 utilize a simple vane-less cast volute, as is common in the turbocharger industry. 
The turboalternators are grouped in pairs; with the "HP-set" (stage 1 and 2) upstream of the first pass through the receiver, and the "LP-set" (stage 3 and 4) positioned between the two receiver passes. The stages 1 or 3 turboalternators contain variable area nozzles, while the down stream turboalternator is closely coupled to its exit pipe, and requires no variable geometry. These housings, operating at lower temperature, resemble the simple turbine housing castings of a turbocharger.

The turbo-alternator layouts are shown in Figure B2 and B3. Figure B2 illustrates the variable area nozzle (VAN) as employed in Stages 1 and 3. Figure B3 illustrates the turboalternator used in Stages 2 and 4. These turboalternators contain the same rotor group, but have the simpler turbocharger-like housings.

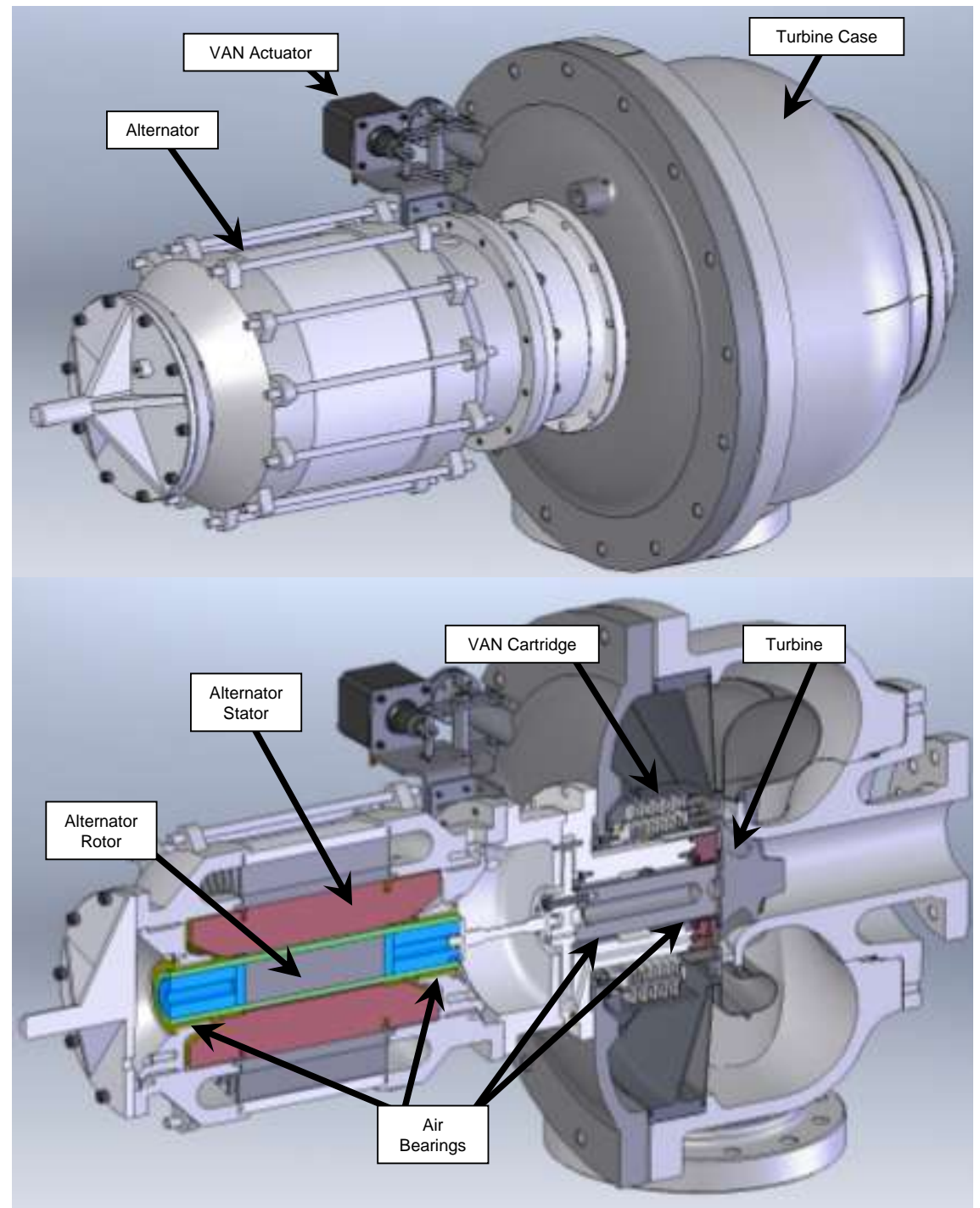

Figure B2. The final design of the SolarCAT turbo-alternator for Stages 1 and 3 (HP1 and LP1). All four spools share identical alternator spools and bearing rotor systems, the turbine ends differ for aerodynamic reasons. Stages 1 and 3 contain variable area nozzles, as shown. 


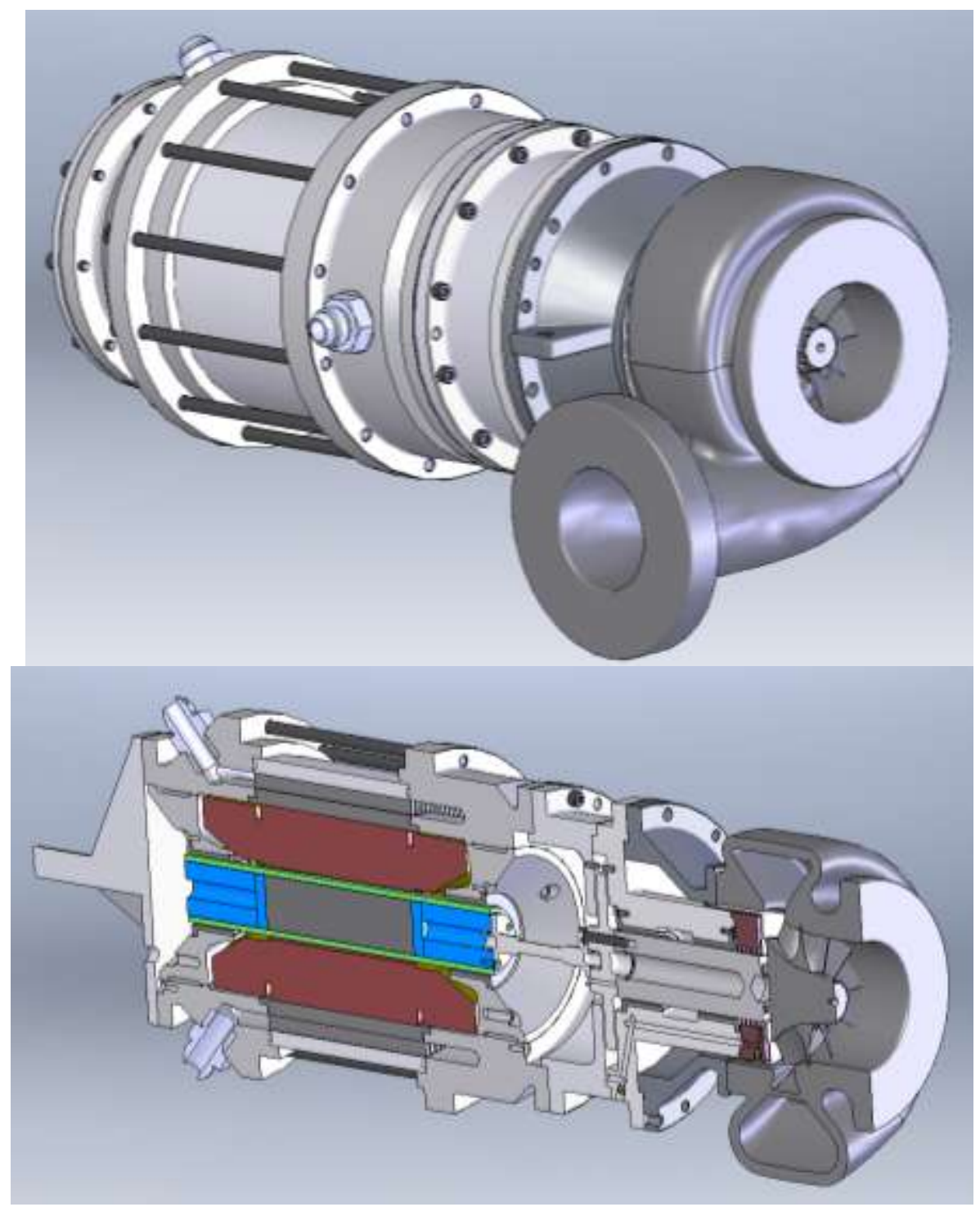

Figure B3. Stage 2 and 4 (HP2 \& LP2) turboalternator and cross section. Unlike the stages 1 and 3 , the turbine end is a simple cast volute without nozzle vanes. This drawing is actually stage 4 . It differs from stage 2 only by its larger turbine housing flow area.

\subsubsection{Turbine Rotor Mechanical Design and Life Analysis}

The four turbine rotors are remarkably similar to one another, especially regarding the features that impact their durability and life.

- Same diameter (+/- 2mm)

- $\quad$ Same speed (RPM) 
- Same material

The principal distinction between the turbine rotors is evident in the blade height. The blade height increases from the first to the last turbine as the gas expands through the series of turbines. Otherwise, the four turbines employed in the SolarCAT are similar in geometry to designs used in the microturbine industry. By design selection, the operating temperatures and stresses are equivalent to or lower than those employed in the microturbine industry. Brayton has performed a finite element stress analysis of the SolarCAT turbines. Based upon the SolarCAT operating specification, experience suggests that creep will be the life-limiting mechanism.

The finite element analysis model is presented in Figure B4, showing the stress results for stage 4; the highest stressed of the four rotors. This analysis shows a relative high peak stress at the blade root. It is believed that this design can be improved with a more optimum fillet. This work is ongoing and will be complete before the release to manufacturing.

The summary of the four turbine stress and life analysis is shown in Table 2. The creep life prediction is based upon the consideration of two common radial turbine alloys; Alloy-713 and MARM-247. Alloy-713C, commonly used in turbochargers is less expensive. MARM-247, with higher creep properties, is the standard choice in the microturbine industry.

In addition to the creep criterion, there are other life-limiting mechanisms involved in the design of a radial turbine. Principally, these are fatigue and oxidation. With only one cold-start per day, the SolarCAT should experience equal to or less severe thermal cycling than a typical microturbine. Though the SolarCAT operates at similar temperatures as a typical microturbine, the significant reduction in moisture content in the air should result in a significant life extension for the turbine hot section. The ambient of water vapor is essentially removed by the intercoolers in the SolarCAT. The water vapor partial pressure from combustion gas is not exposed to stage 1 and 2 turbines, and is very low on stages 3 and 4 . Furthermore hybrid operation is limited to a few hours per day. 


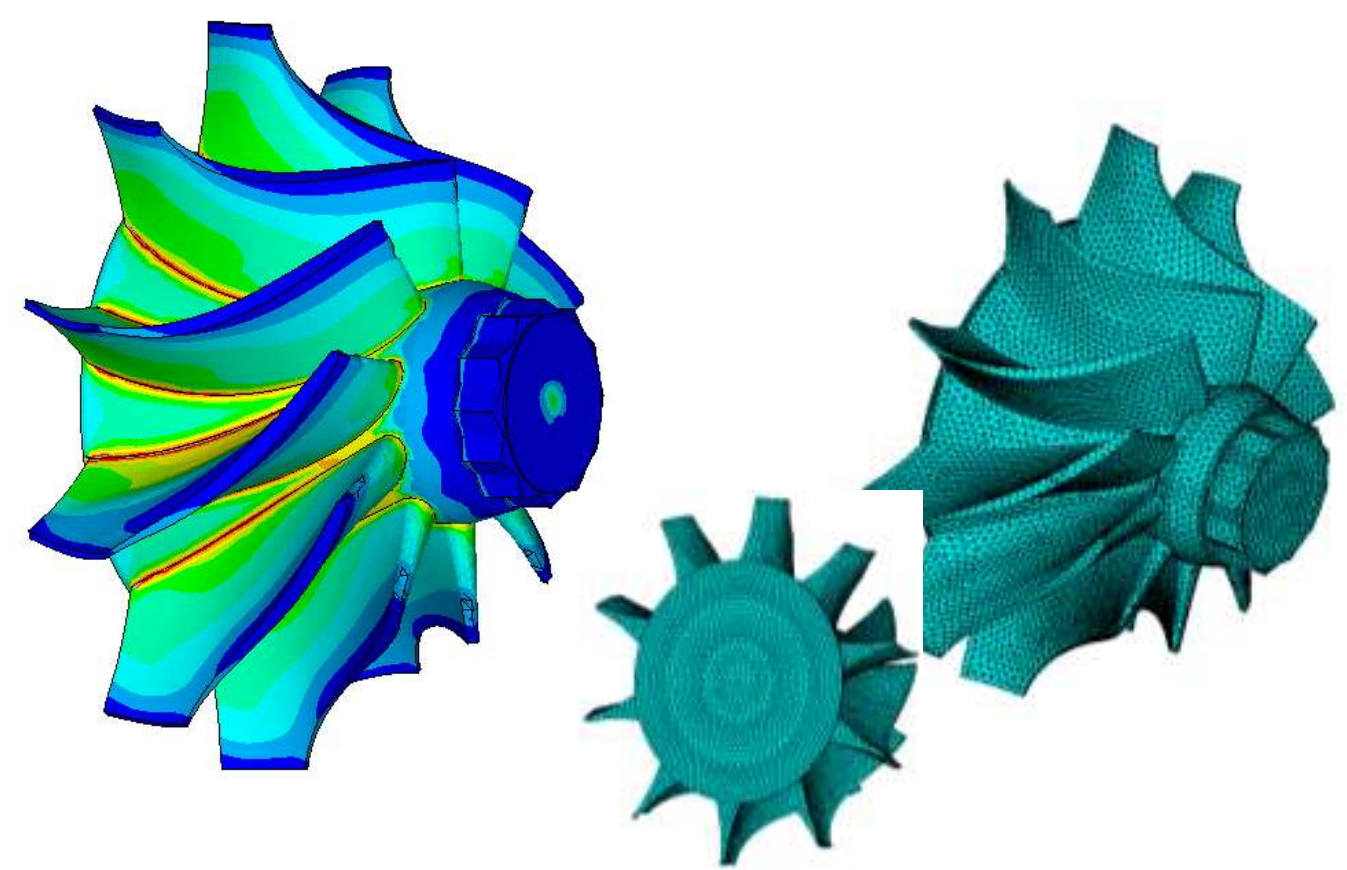

Figure B4 Stress analysis of Stage 4 turbine rotor. This rotor has the tallest blades of the four, and hence experiences the highest stress levels. The high local stress at the blade root shows the acute stress level prior to optimizing the fillet radius. These refinements will be completed before procurement. Even with this less than optimum geometry, the rotor meets creep life targets.

Table B2 Turbine creep life summary, based on FEA results

\begin{tabular}{|l|r|r|r|r|}
\hline & \multicolumn{1}{|c|}{ HP1 } & \multicolumn{1}{c|}{ HP2 } & \multicolumn{1}{c|}{ LP1 } & \multicolumn{1}{c|}{ LP2 } \\
\hline SolarCAT Stage & 1 & 2 & 3 & 4 \\
\hline Gas Inlet temp, K & 1200 & 1044 & 1200 & 1044 \\
\hline T_hub_ref, K & 1061 & 923 & 1061 & 923 \\
\hline Gas out temp, K & 1044 & 883 & 1044 & 883 \\
\hline ER & 1.97 & 2.16 & 1.93 & 2.23 \\
\hline RPM & 116000 & 116000 & 116000 & 116000 \\
\hline Dtip, mm & 73 & 76.1 & 81.2 & 81.2 \\
\hline Dex, mm & 38 & 65.7 & 65.5 & 72.4 \\
\hline hub dia, mm & 14.8 & 14.1 & 26 & 26.4 \\
\hline Utip, m/s & 443.4 & 462.2 & 493.2 & 493.2 \\
\hline Uex, m/s & 230.8 & 399.0 & 397.8 & 439.7 \\
\hline Root Stress, MPa & 102.2 & 343.7 & 301.6 & 379.3 \\
\hline & & & & \\
\hline Creep life with IN713C & $1.70 \mathrm{E}+06$ & $4.03 \mathrm{E}+06$ & $3.22 \mathrm{E}+03$ & $2.44 \mathrm{E}+07$ \\
\hline Creel Life with MARM247 & $1.68 \mathrm{E}+07$ & & $6.56 \mathrm{E}+04$ & \\
\hline
\end{tabular}

In conclusion, the SolarCAT turbine rotors should exceed the 40,000 hour product life specification. At this stage of the design, Alloy-713C is acceptable for the two lower temperature stages $(1,2,4)$, while MARM-247 appears to be the safe choice for the higher temperature stage (3), due to the high stress and temperature. 


\subsubsection{Variable Area Nozzle}

The variable area nozzle is an important element of turboalternator, employed in stages 1 and 3. The VAN permits efficient control of the flow through the turbomachine, enabling efficient turbine operation to solar insolation levels below $20 \%$ of the nominal rating. The assembly is shown in figure B5. Modeled after successful automotive turbocharger VANs, this design overcomes the chief source of aerodynamic losses in those products. This normal loss is the result of leakage over the tops of the movable vanes. In automotive turbocharger applications, where dynamic response is of paramount importance, these clearances must be large enough to allow free movement the vane during transients. The patented Brayton design similarly uses articulating vanes, but during the substantial dwell periods anticipated in the solar/hybrid operation, the bellows internal pressure clamps the vanes against the shroud, preventing axial movement and vane leakage. When a significant change on solar insolation occurs, the internal bellows pressure is vented, causing the van assembly to retract about 0.5 to $1 \mathrm{~mm}$, thereby enabling the vanes to freely move to the preferred position. Once in position, the bleed air is stopped and the bellows re-clamps the vanes for efficient performance.
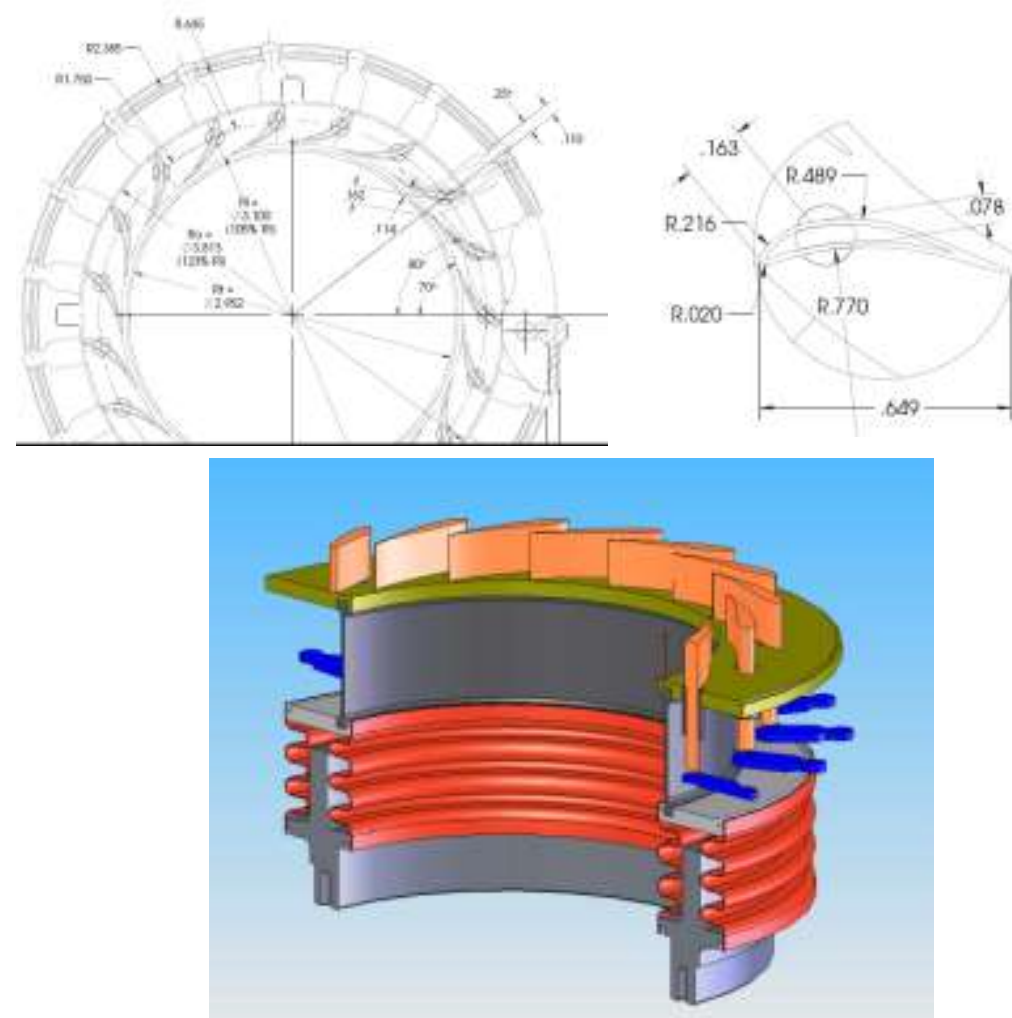

Figure B 5 Brayton's high efficiency variable area turbine nozzle, configured for SolarCAT stages 1 and 3 . This design is covered by various US patents. 


\subsubsection{Turbine Housing Analysis}

Each of the four turbine housings have unique aerodynamic features, and manage different pressures and temperatures associated with the staged expansion. There are two general housing configurations in the SolarCAT package. The high-temperature stages, 1 and 2 require internally insulated cast housings. The aerodynamic features of the volute are inside the pressure boundary, surrounded by insulation. The down-stream stages, 2 and 4 operate at considerably lower inlet temperature and thus meet their life requirements with externally insulated housings, much like that used in the turbocharger industry.

\subsubsection{Internally Insulated Housings - Stages 1 and 3}

The stage- 1 and stage- 3 turbine housing as are internally insulated to protect pressure boundaries from the peak gas temperatures. The analytical model and the solid model, from which it was derived, are shown in Figure 6 below.

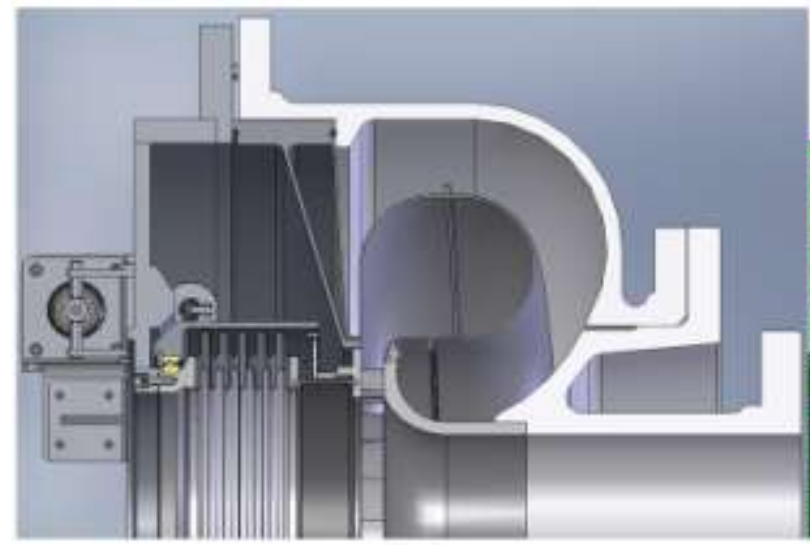

(a)

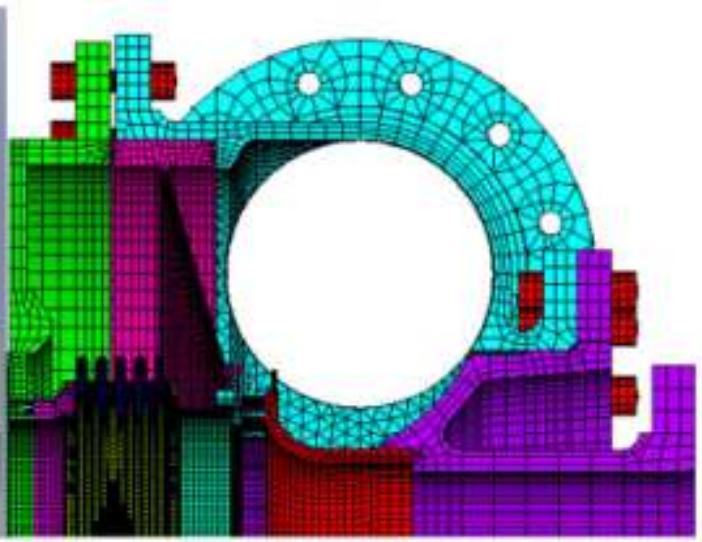

(b)

Figure 6. (a) An electronic solid model of the stage-3 turbine housing assembly, and (b) the finite-element model of the assembly used for thermal analysis.

Temperatures and equivalent convection coefficients were imposed on the finite element model to determine the temperature field shown in Figure 7. 


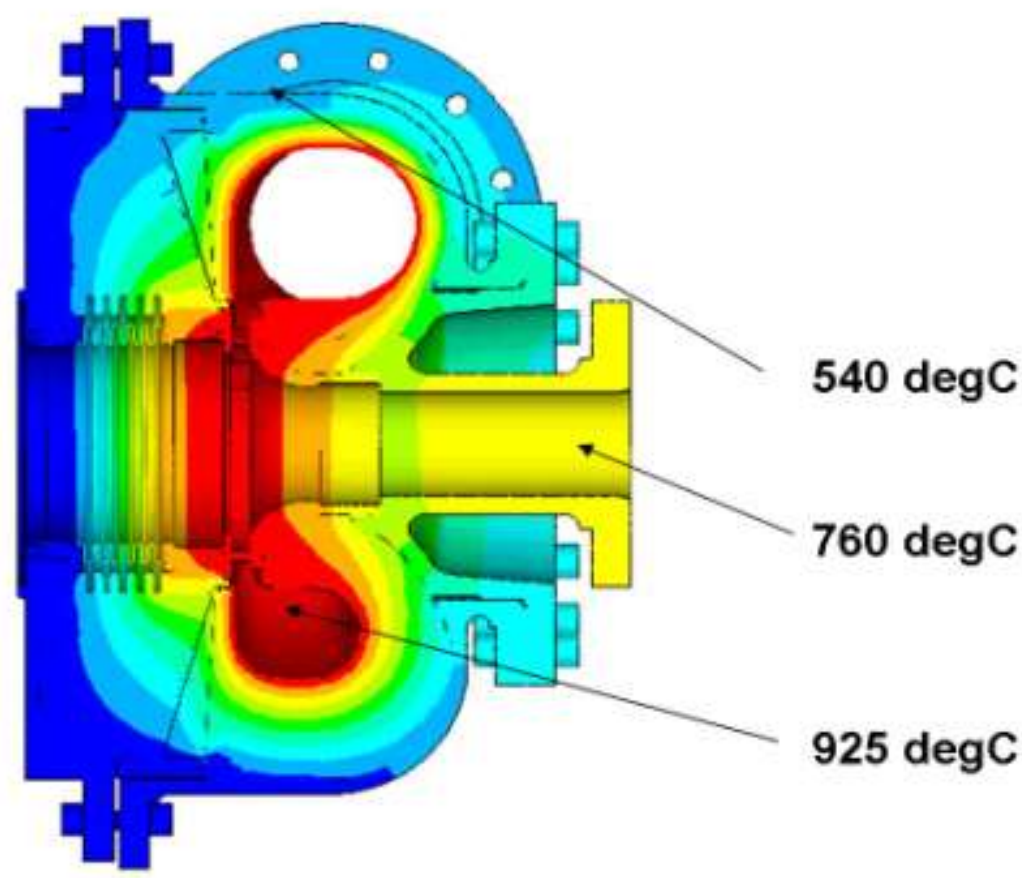

Figure 7. Thermal results for the stage-3 turbine static structures.

Finite-element thermal and pressure analyses were performed for the larger Stage-3 housing in order to develop features needed to manage stress levels. These analyses assessed the higher pressures specified for the stage-1 housing as well, providing a basis for scoping analysis for that stage in addition to the explicit results for stage 3. The results are shown in Figure B8 and Table B3.

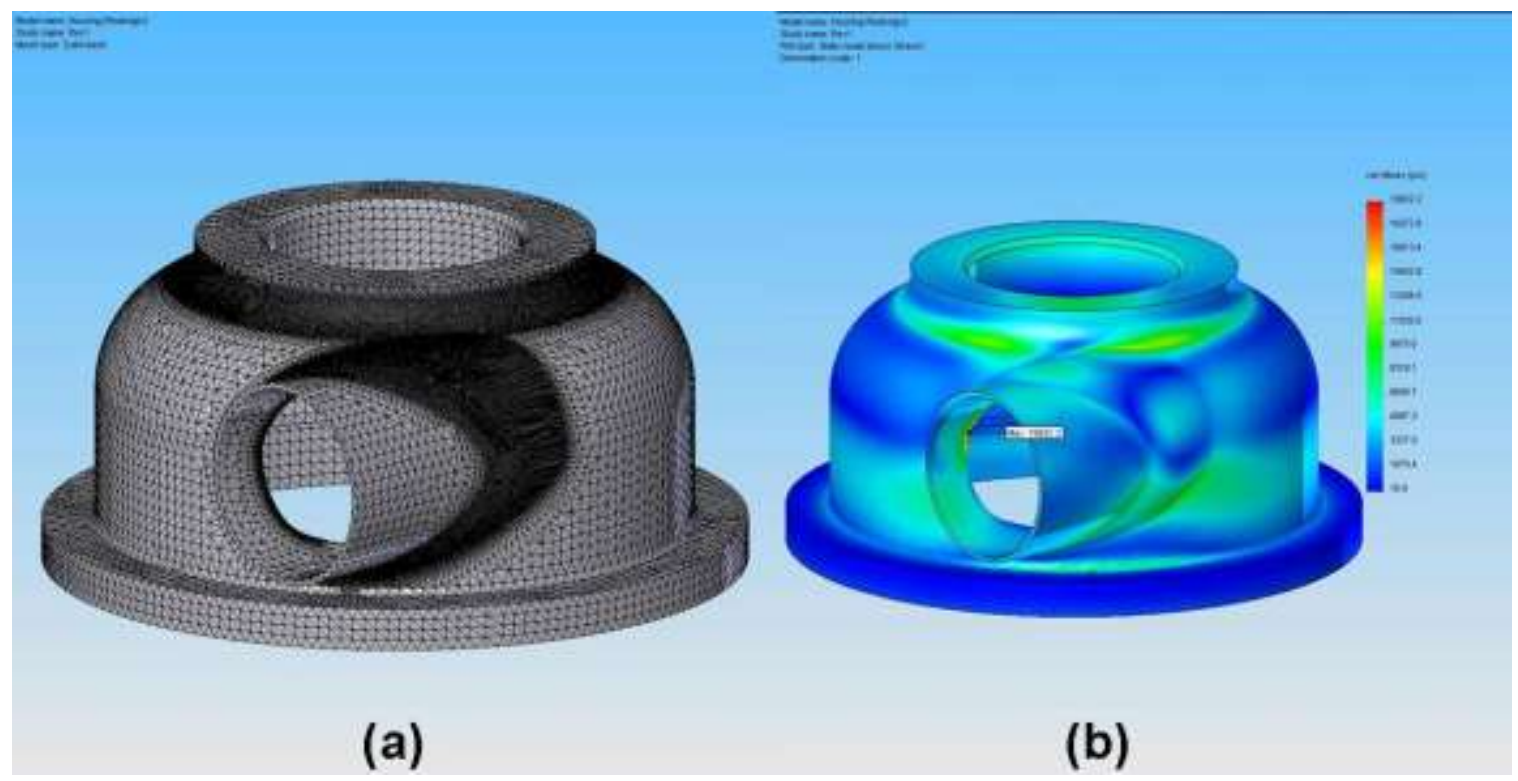

Figure 2. (a) The meshed finite-element model representing the developed housing geometry for stage-3. (b) Stresses on the stage-3 housing at the more strenuous stage-1 pressures. (Temperatures are similar for stages 1 and 3 ) 
Alloys for stage- 1 and stage- 3 housings are Inconel 713LC and Alloy X respectively. Both meet the 40,000 hour service-life requirement for the product, suggesting no change-out will be required.

Table B1. Durability Summary - Insulated Turbine Cases

\begin{tabular}{|l|c|c|}
\hline & Stage 1 & Stage 3 \\
\hline Inlet Gas Pressure, $\mathrm{kPa}$ & 1907 & 471 \\
\hline Inlet Gas Temperature ${ }^{\circ} \mathrm{C}$ & 925 & 925 \\
\hline Peak Stress, MPa & 105 & 34 \\
\hline Controlling Metal Temperature, ${ }^{\circ} \mathrm{C}$ & 760 & 760 \\
\hline Material & $713 \mathrm{LC}$ & Alloy X \\
\hline Creep Life, hr & $>40,000$ & $>40,000$ \\
\hline Creep Stress Margin & $97 \%$ & $21 \%$ \\
\hline
\end{tabular}

\subsubsection{Externally-Insulated Vaneless Housing - Stages 2 and 4}

Stages 2 and 4, with their lower firing temperatures, are cast in volute forms, with serve as both pressure and flow boundaries. As in-flow turbines the structure containing the pressure is also wetted by the hotter incoming gases. To assess this construction, a series of scoping analyses were performed using finite-element cyclic-symmetric models, configured, approximately, as ribbed toroids open at the inner diameter, with pipe stubs appended on the axis at both ends. An example is shown in Figure 11. Based on rigorous analyses of similar housings, maximum creep strain occurs 180-degrees from the so-called tongue, the short, supported section of the minor-diameter. This section of the stage- 2 and stage- 4 housings was selected as representative for the scoping analyses reported here. The challenge, generally, is to control creep deformation that tends to open the vaneless nozzle passage represented by the axial space at the inner diameter. 


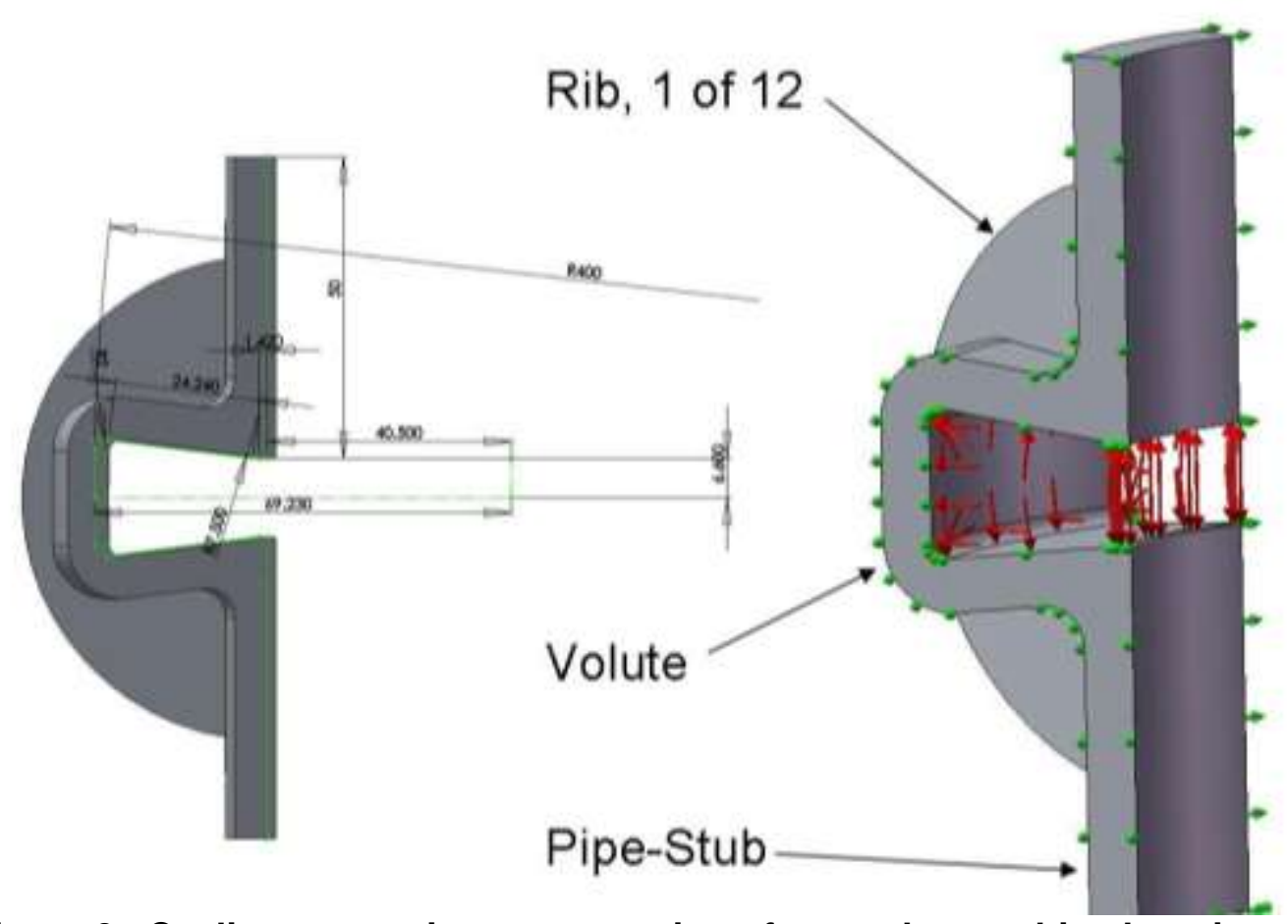

Figure 3. Cyclic-symmetric representation of a vaneless turbine housing used for durability scoping analysis.

Results of the analyses conducted isothermally and with a uniform internal pressure, are presented graphically in Figure 12, and show stress contours on an exaggerated displaced shape. With the lower gas pressure of stage 4, supporting ribs can be eliminated. Quantitative results for stage- 2 and stage- 4 housings are presented in Table 4.

Stress magnitudes predicted by these analyses appear low, judging by experience with similar parts and loadings. The addition of strain-controlling thermal loads will elevate stress above those predicted in the scoping analysis with pressure at a uniform temperature, reducing margins. These will be assessed in more rigorous analyses. 

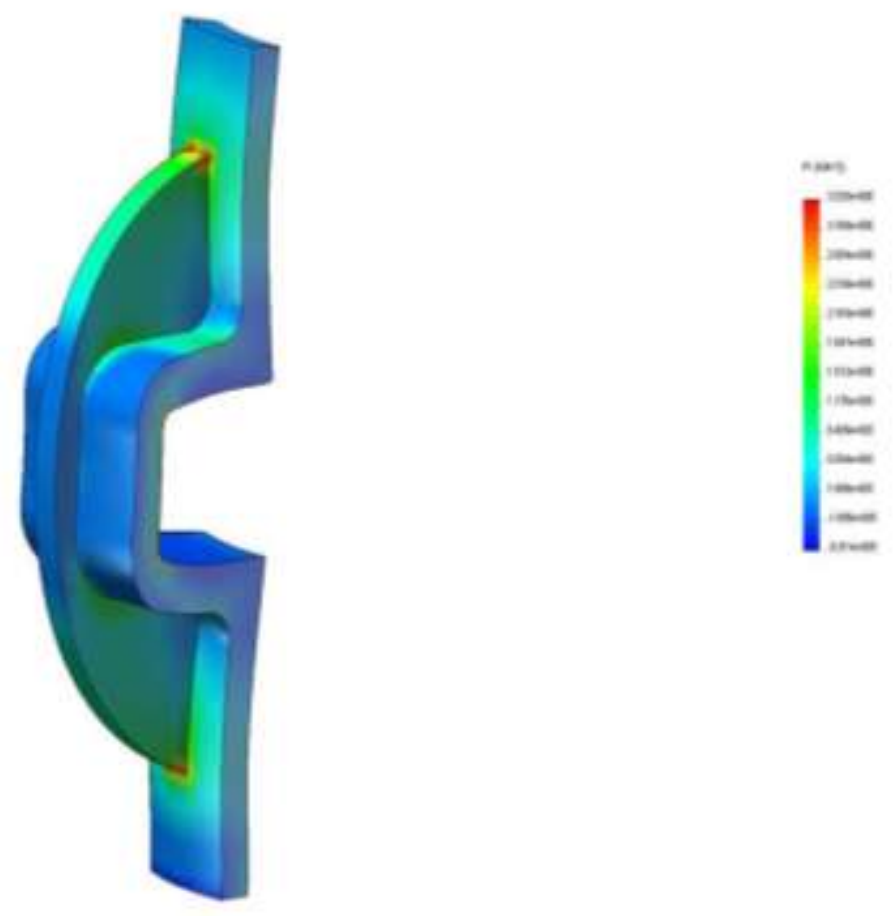

Figure 4. Example of a displaced stress plot for a cyclic-symmetric analytical representation of the stage-2 ribbed, vaneless, volute housing.

Table 2. Durability Summary - Vaneless Turbine Housings

\begin{tabular}{|l|c|c|}
\hline & Stage 2 & Stage 4 \\
\hline Inlet Gas Pressure, $\mathrm{kPa}$ & 948 & 234 \\
\hline Inlet Gas Temperature ${ }^{\circ} \mathrm{C}$ & 760 & 760 \\
\hline Peak Stress, MPa & 13 & 5 \\
\hline Controlling Metal Temperature, ${ }^{\circ} \mathrm{C}$ & 760 & 760 \\
\hline Material & Alloy X & CF8M \\
\hline Creep Life, hr & $>40,000$ & $>40,000$ \\
\hline Creep Stress Margin & $214 \%$ & $40 \%$ \\
\hline
\end{tabular}

\subsubsection{Turbine housing manufacturing status}

The turbine housings represent one of the most expensive elements of the SolarCAT product. Our life studies indicate that at least the first three stages should be cast from a high nickel alloy such as Hastelloy-X . The fourth stage (LP2) would meet all life specifications with a lesser stainless alloy.

Each of the housings is to be made from an air-melt sand cast process. At the printing of this report, only the Stage 3 housing (LP1) has been tooled and cast. Some photos of the raw castings are provided in Figure 13. The Hast-X raw castings will cost about $\$ 30$ to 
$40 / \mathrm{lbm}$ in production quantities. The lower temp alloy should be about $70 \%$ of that price. Final machining involves turning the shroud contour and finishing the flanges. In a highly tooled environment, such as turbocharger manufacturing center, these operations take only a few minutes per part. At SolarCAT quantities, (500 unit lots), the set-up time and the slower cutting speeds of Hast-X will add \$100 to \$200 to the cost of the part.
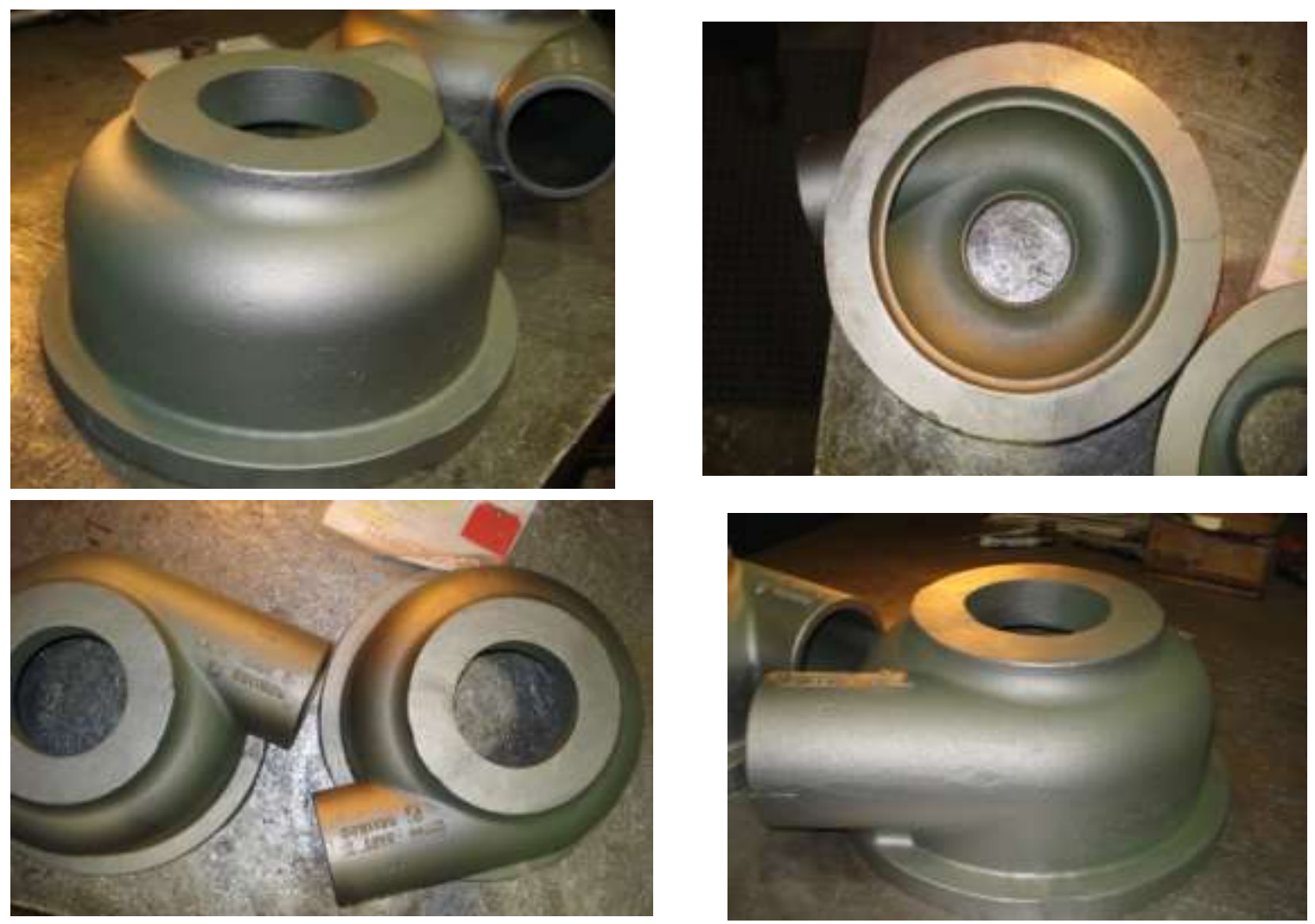

Figure 5 - SolarCAT Stage-3 turbine housing, case from Hastelloy-X. The diameter is about 10 inches.

\subsubsection{Bearing design and testing}

The test article is shown in Figure 14. This is a complete mechanical assembly of the 53 kWe SolarCAT turboalternator; without the high temperature turbine rotor and housing. For test purposes, this test article has a low-temperature air turbine, configured to have similar weight and moment of inertia of the actual hot turbine rotor. It has been designed to operate without lubricants or coolants, incorporating air bearings and an air-cooled alternator. Air bearings seemed to be the natural choice, as they have been proven to achieve exceptionally long life and service intervals in the microturbine applications. Moreover, the avoidance of liquids on the focal plane eliminates concerns related to the natural orientation changes associates with solar tracking. 


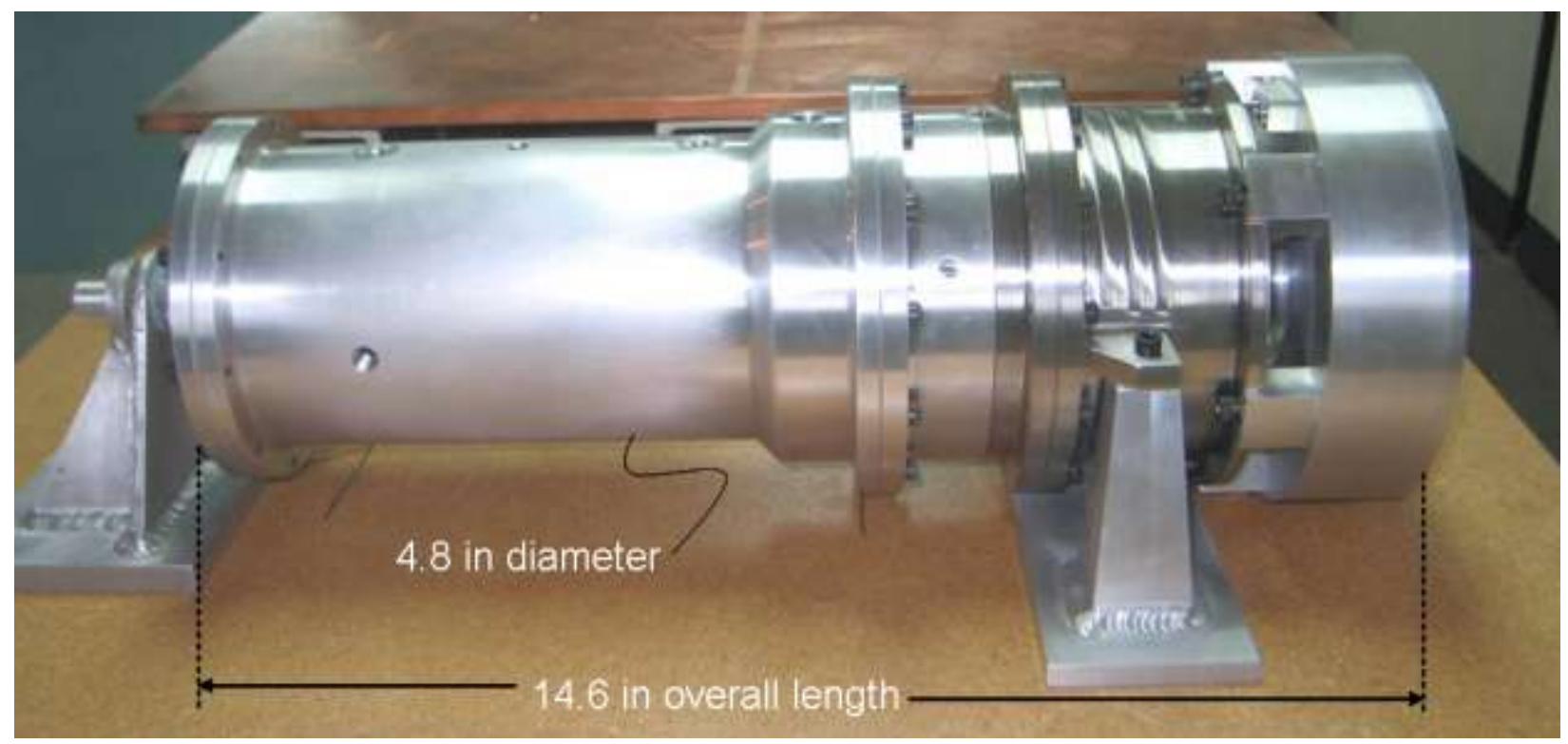

Figure 6. Assembled turbo-alternator simulator. This contains the alternator and complete bearing system. Over 100 hours of hot and cold rotor testing was performed, covering the entire speed map up tp 120,000 RPM.

The full mechanical assembly has been run at $20 \%$ over-speed (140,000 RPM). This test validated rotor dynamics models and confirmed the feasibility of the air bearing design. Additionally, the bearing mechanical losses were estimated to be less than $50 \mathrm{~W}$ per bearing at steady state operating conditions. The testing validated the system dynamic modeling.

Addition mechanical analyses included the following:

- A steady-state thermal analysis of the rotor system. This concluded that alternator magnets will operate within rated limits.

- A turbine thrust balance analysis has provided necessary loads for proper sizing of the thrust bearing. These loads have been successfully demonstrated on the air bearing test rig.

- Bearing stability has demonstrated over the full dynamic range.

- Within the intended operating range, nominally 95,000 RPM to 120,000 RPM, the vibration levels were below the target levels ( 0.5 ips).

- No structural or fatigue damage was observed after five excursions to 140,000 RPM (20\% over-speed).

- A compressor bleed-flow of $<1 \%$ was found to be adequate to maintain alternator magnet temperatures within acceptable levels. 


\section{Appendix C - Phase 1 Solar Receiver Design}

\subsubsection{Receiver Design Concept}

The solar receiver is based on a novel design approach proposed by Brayton Energy. The 'wrapped cone' concept pictured in Figure C1. A model for predicting receiver heat transfer and pressure loss is described in this section. A finite element stress analysis and computational fluid dynamic analyses have also been preformed. The mathematical algorithms describing the tube geometry have been incorporated into SolidWorks; a parametric CAD software model. This geometry has undergone concurrent thermal analysis and manufacturing evaluations.

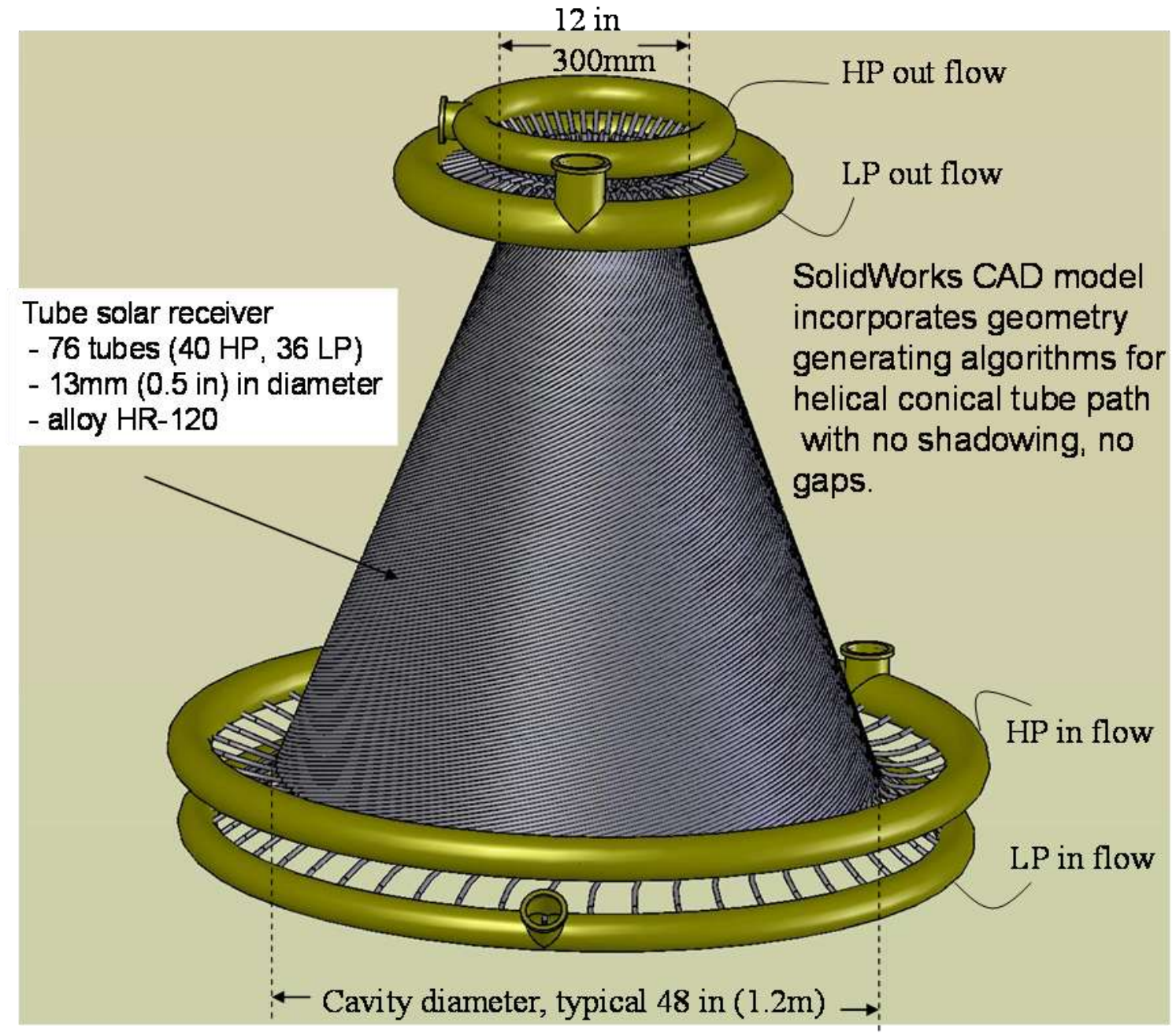

Figure 7. Brayton's 'wrapped-cone' concept for solar receiver. Preliminary dimensions are shown on the illustration. Dimensions are preliminary as discussed in text. 


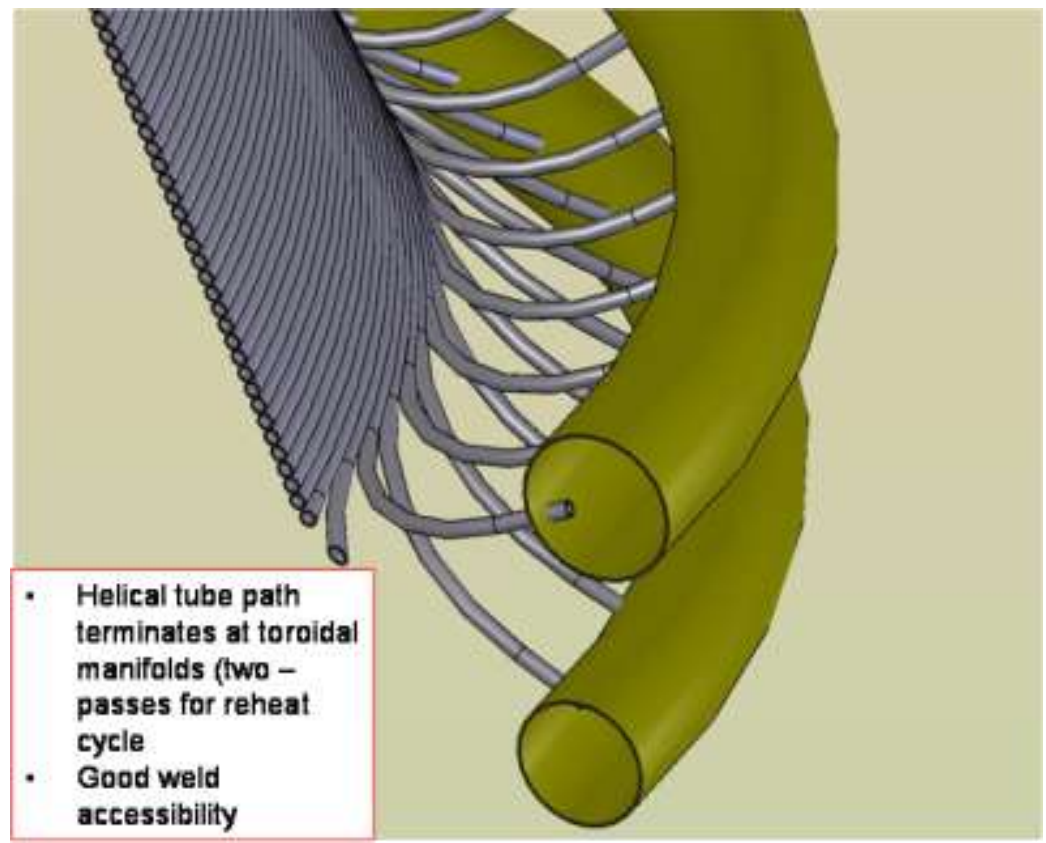

Figure 8. Helical tube solar receiver showing tube terminations at toroidal manifolds

Design principles for the proposed solar receiver are as follows:

- Focused solar radiation impinges on the inside surface of the 'truncated cone' shown in Figure C3. The cone surface is a contiguous layer of metal tubes carrying high-pressure air. The tube geometry is defined such that the parallel rows of tubes are edge to edge, with no gaps or overlapping.

- A conical shell of ceramic board insulation backs the tube bundle. Inevitably, as the tubes thermally expand, some solar flux harmlessly passes through the minor gaps between the tubes.

- The helical tube lengths tolerate the significant differential thermal expansion, imposing minor stress on the joints.

- The absorbing cavity surface is enlarged to moderate the flux on the tube walls, matching the matching the internal convection to control wall temperature. This trade is the principal optimization objective; to minimize tube wall surface temperature and pressure drop.

- Air at stations 2 and 4 enters the tubing at the base of the cone. Air temperature rises progressively to turbine-inlet temperature at the discharge end of the tubes, located at the top of the cone 
- The tubes are split roughly evenly between the high and low-pressure heat addition sides of the cycle. Their relative number is governed by the respective thermal splits.

- The flux distribution is assumed to be axisymmetric. Naturally occurring circumferential variations are not expected to impact the power absorption splits significantly, as the tube count is large (60 to 200) and intense radiation leveling occurs within the cavity.

- The exterior of the cone is surrounded by a layer of thermal insulation.

Receiver dimensions appearing in Figure C1were determined in the course of the study described below. As will be discussed, these may be considered preliminary pending the development of a model for incident thermal flux.

Under earlier solar dish-Brayton development efforts ${ }^{56}$, receiver designs relied on containment of high-pressure air behind a quartz window, with heat transfer accomplished through direct radiation impingement on an extended surface in contact with flowing air. Tube-type receivers were built with some success for solar Brayton demonstrations; however the pressure drop within the tubes was a serious problem for the low pressure ratio microturbine candidates. For the same principles that yield a small recuperator, the tubular receiver design is less challenging as cycle pressure ratio increases and mass flow per unit power drops.

Compared to the prior window-based strategy, the proposed receiver concept offers compelling advantages as follows:

- It is much less susceptible to catastrophic (and possibly hazardous) single-point failures, e.g. fracture of the quartz window. Ruptured tubes could be replaced on an individual basis. Also, unlike Stirling receivers, there would be no consequential loss of expensive and/or hazardous working fluids.

- The receiver aperture can be formed from an expendable insulation board or silicon carbide slab. Unlike windowed receivers incorporating sealing flanges at the aperture, solar spillage and tracking errors is not damaging.

- Unlike a windowed receiver, the simple tubular receiver may have a large aperture. Though this represents an efficiency loss, the looser concentrating accuracy specification should lower dish cost, especially for the large dishes.

\footnotetext{
${ }^{5}$ A Solarized Brayton Engine Based on Turbo-Charger Technology and the DLR Receiver, Gallup, D.R. and Kesseli, J.B., Proceedings of the IECEC, AIAA-94-3945-CP, Monterey, CA. (1994).

${ }^{6}$ Sanders Associates, Parabolic Dish Module Experiment, Final Report, Sandia National Laboratories, Albuquerque, NM, by James Kesseli, Bear Davis, Don Ross Sander Associates, 1986. Report SAND857007.
} 
- It is readily adaptable to a multi-pass design, as required for implementation of the reheat cycle. This would pose a formidable challenge under a window-based strategy.

- The tubular design requires no pressure vessels. In contrast, window receivers incorporate a large (>1meter), and extremely heavy ASME-coded pressure vessel.

- Receiver weight is low, an important consideration given that the power module imposes a cantilever load on the dish support structure. Reducing the weight of the power conversion system has a positive impact on the dish cost.

- Its manufacturing costs will almost certainly be lower, as the quartz window for the size receiver has been quoted at $\$ 5000$ for very large quantities. 